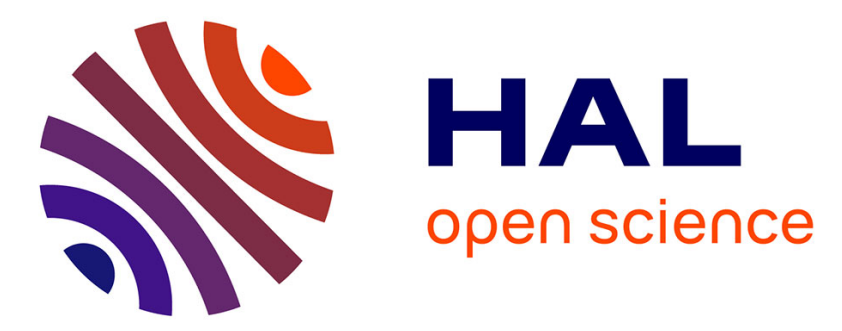

\title{
L'habitat rural mérovingien de Fresnoy-le-Grand (Aisne) "Les Champs à Grès"
}

Thierry Galmiche, Gilles Desplanque, Gaëtan Jouanin, Amélie Corsiez

\section{To cite this version:}

Thierry Galmiche, Gilles Desplanque, Gaëtan Jouanin, Amélie Corsiez. L'habitat rural mérovingien de Fresnoy-le-Grand (Aisne) "Les Champs à Grès ". Revue archéologique de Picardie, 2010, 1-2, pp.195 - 221. 10.3406/pica.2010.3210 . hal-03261459

\section{HAL Id: hal-03261459 \\ https://hal.science/hal-03261459}

Submitted on 15 Jun 2021

HAL is a multi-disciplinary open access archive for the deposit and dissemination of scientific research documents, whether they are published or not. The documents may come from teaching and research institutions in France or abroad, or from public or private research centers.
L'archive ouverte pluridisciplinaire HAL, est destinée au dépôt et à la diffusion de documents scientifiques de niveau recherche, publiés ou non, émanant des établissements d'enseignement et de recherche français ou étrangers, des laboratoires publics ou privés. 


\section{L'habitat rural mérovingien de Fresnoy-le-Grand (Aisne) "Les}

Champs à grès"

Thierry Galmiche, Gilles Desplanque, Gaëtan Jouanin, Amélie Corsiez

\section{Citer ce document / Cite this document :}

Galmiche Thierry, Desplanque Gilles, Jouanin Gaëtan, Corsiez Amélie. L'habitat rural mérovingien de Fresnoy-le-Grand (Aisne) "Les Champs à grès". In: Revue archéologique de Picardie, n¹-2, 2010. pp. 195-221;

doi : 10.3406/pica.2010.3210

http://www.persee.fr/doc/pica_0752-5656_2010_num_1_1_3210

Document généré le 05/01/2018 


\title{
Zusammenfassung
}

Am Fundplatz "Champs à Grès » in Fresnoy-le-Grand (Departement Aisne) wurden zwei unterschiedliche Siedlungsstrukturen nachgewiesen. Die erste wird in das 3. Jh. n. Chr. datiert und entspricht dem Randbezirk eines landwirtschaftlichen Betriebs. Die untersuchten Strukturen bestehen aus Parzellengräben, Feuerstellen, einigen Gruben und einem Vorratsraum. Zudem wurden Brandgräber und ein Körpergrab freigelegt. Zwei Gräber aus dem 1. Jh. n. Chr. legen eine frühe Besiedlung dieses Areals nahe. E s wurden ebenfalls Überreste aus merowingischer Zeit gefunden. Sie hören zu einem Gehöft, das von der zweiten Hälfte des 6. Jh. bis zur Mitte des darauffolgenden Jahrhunderts oder sogar bis zum Beginn des 8. Jh. existiert hatte. Acht Hütten und ein größerer eingetiefter Bau wurden freigelegt. Es ist nicht auszuschließen, dass am Südrand des Areals ein Pfostenbau gestanden hatte. Der ergrabene Bereich war recht klein, deshalb kann nicht ausgeschlossen werden, dass außerhalb des Areals eine oder sogar mehrere weitere bäuerliche Strukturen existiert haben. Zwischen dem 3. und der zweiten Hälfte des 6. Jh. wurde eine Unterbrechung der Siedlungskontinuität aufgezeigt. Die merowingische Siedlung erscheint in diesem Licht als die Neubesiedlung

eines seit dem 3. Jahrhundert aufgegebenen Ortes. Diese Tendenz lässt sich vielleicht durch die erneute Bewirtschaftung bereits in früheren Zeiten genutzter Böden erklären.

\section{Résumé}

Deux occupations distinctes ont été mises en évidence sur le site des "Champs à Grès" à Fresnoy-le-Grand (Aisne). La première, du Ille siècle après J.-C., correspond à la périphérie d'une exploitation agricole. Les vestiges étudiés consistent en des fossés parcellaires, des foyers, quelques fosses et un cellier. Des sépultures à crémation et une tombe à inhumation ont également été mises au jour. La présence de deux tombes du ler siècle après J.-C. permet peutêtre d'envisager une occupation précoce du secteur. Des vestiges de l'époque mérovingienne ont aussi été trouvés. Ils appartiennent à une unité agricole dont la durée de vie s'étend de la seconde moitié du Vle siècle au milieu du siècle suivant, voire au début du VIIle siècle. Huit cabanes et un bâtiment excavé de plus grande taille ont été découverts. La présence d'un bâtiment sur poteaux en bordure méridionale du site est possible. Au vu de la faible superficie étudiée, l'existence d'un ou plusieurs autres noyaux agricoles situés en dehors de l'emprise de fouille n'est pas exclue. Un hiatus a été mis en évidence entre le Ille et la seconde moitié du Vle siècle. L'implantation mérovingienne apparaît ainsi comme la réoccupation d'un site abandonné depuis le llle siècle. Cette tendance s'explique, peut-être, par une remise en valeur de terres anciennement exploitées.

\begin{abstract}
Two different levels of occupation have been revealed on the site of the "Champ à Grès" at Fresnoy-le-Grand (Aisne). The first one, dating from the IIIrd century A. D., corresponds to the periphery of a farm. The remains studied consist in boundary ditches, hearths, a few pits and a cellar. Some cremation tombs and a single inhumation tomb have also been excavated. The existence of two Ist century A. D. tombs may possibly indicate an early occupation of this part of the site. Some remains from the Merovingian period have also been discovered. They belong to a farming unit which lasted from the second half of the $\mathrm{VI}$ th century to the middle of the following century, perhaps even to the beginning of the VIIIth century. Eight huts and a larger excavated building have been found. There may have been a construction built on posts on the south edge of the site. Taking account of the small surface excavated, the existence of one or several other farming units, outside this area, cannot be ruled out. There appears to be a gap between the IIIrd century and the second half of the VI th century. The Merovingian occupation thus appears to be the reoccupation of a site abandoned since the IIIrd century, which seems to indicate a tendency to redevelop previously farmed lands.
\end{abstract}

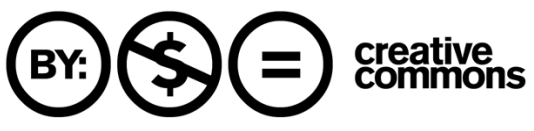




\title{
L'HABITAT RURAL MÉROVINGIEN DE FRESNOY-LE-GRAND (AISNE) "LES CHAMPS À GRÈS"
}

\author{
Thierry GALMICHE, Gilles DESPLANQUE, \\ Amélie CORSIEZ \& Gaëtan JOUANIN
}

La commune de Fresnoy-le-Grand se situe dans le Vermandois (fig. 1) dont le paysage s'apparente à un plateau entrecoupé de vallées sèches. Le site archéologique des "Champs à Grès" se trouve sur le flanc d'une de ces vallées. Il a été découvert en décembre 2006 lors du diagnostic préalable à l'aménagement, par le Département de l'Aisne, d'une déviation de la RD 8 à Fresnoy-le-Grand. Ces sondages archéologiques ont conduit, en juin 2008, à une fouille exhaustive de la zone concernée par le projet routier, soit $2500 \mathrm{~m}^{2}$ (fig. 2). Le couvert végétal, d'une épaisseur de $30 \mathrm{~cm}$, repose directement sur la craie blanche du Coniacien - Santonien. Des colluvions ont localement été mises en évidence. La seule découverte archéologique réalisée sur le territoire de la commune de Fresnoy-le-Grand concernait des tuiles gallo-romaines mises au jour à $600 \mathrm{~m}$ au nord-ouest du site (FLAMANT 1984). Dans la région, les sites d'habitats mérovingiens les plus proches qui ont fait l'objet d'une publication se trouvent à Goudelancourt-lès-Pierrepont dans l'Aisne (NICE 1994), à Juvincourt-et-Damary dans l'Aisne (BAYARD 1989) et à Athies dans la Somme (Harnay 2009).

Deux occupations successives ont été mises en évidence. La plus ancienne est datée entre la seconde moitié du $\mathrm{I}^{\mathrm{er}}$ siècle et le III ${ }^{\mathrm{e}}$ siècle après J.-C., la seconde entre la seconde moitié du VI ${ }^{\mathrm{e}}$ siècle et le début du VIII siècle après J.-C.

\section{DES STRUCTURES ANTIQUES EN PÉRIPHÉRIE D’UNE EXPLOITATION AGRICOLE}

\section{LES SÉPULTURES À CRÉMATION 2024, 2026, 2040 ET 2058 ET À INHUMATION 2035}

Des esquilles osseuses brûlées et des fragments de céramiques ont été mis au jour dans le remplissage argilo-limoneux des structures 2024, 2026, 2040 et 2058 interprétées comme des sépultures à crémation (fig.3). Circulaires ou rectangulaires, les creusements préalables à l'aménagement de ces sépultures sont conservés sur une profondeur inférieure à $20 \mathrm{~cm}$. Leur taille est comprise entre 40 et $107 \mathrm{~cm}$. L'analyse anthropologique réalisée par Nadège Robin (Département de l'Aisne, chercheur associé UMR

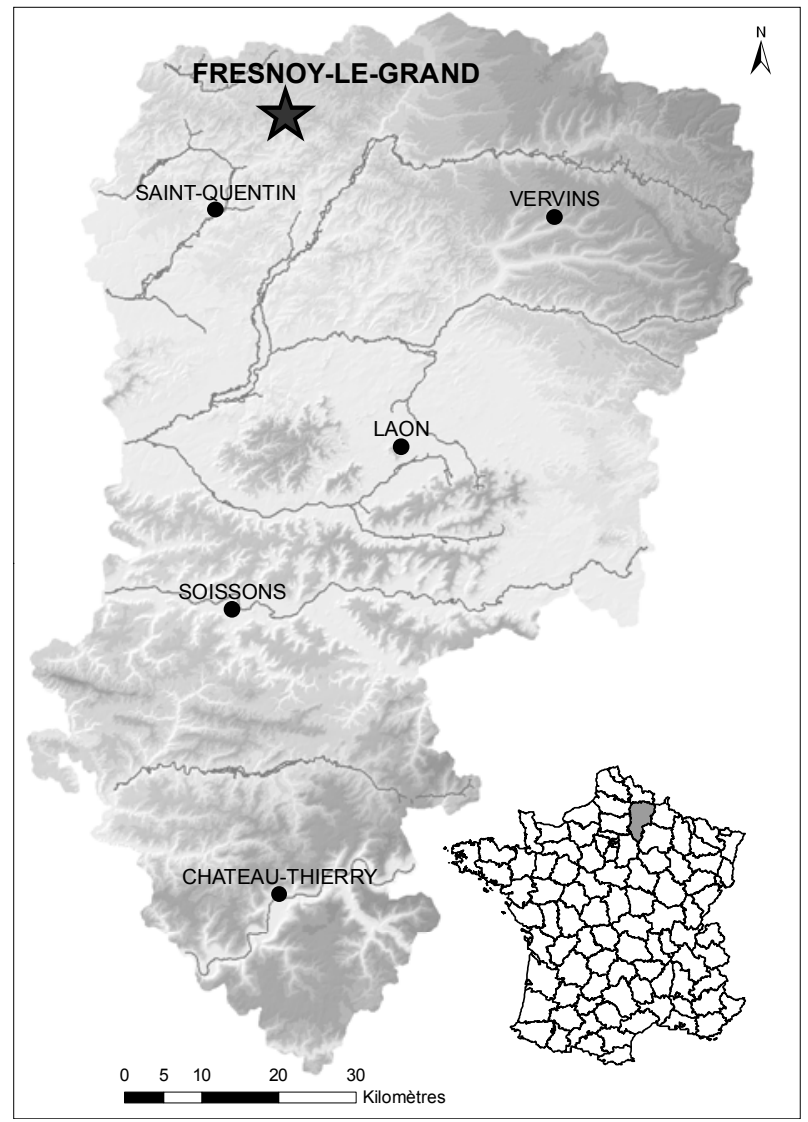

Fig. 1 - Carte de localisation de Fresnoy-le-Grand.

6578) a permis de mettre en évidence des similitudes entre ces structures : même température peu élevée de crémation (entre 520 et $580^{\circ} \mathrm{C}$ ), dépôt en pleine terre (pour 2024 et 2040), état de fragmentation équivalent. Ces ressemblances invitent à considérer ces incinérations comme un ensemble cohérent. L'étude du mobilier a toutefois permis de déceler une différence chronologique entre les structures 2024 et 2058, respectivement datées de la seconde moitié du Ir siècle et du III ${ }^{\text {e }}$ siècle.

Le plan à l'ouverture de la structure 2035 peut être décrit comme un rectangle accolé à une ogive. Sa longueur totale est de 2,3 m et sa largeur maximale de $1,86 \mathrm{~m}$. Son fond plat rectangulaire $(1,43$ sur $0,85 \mathrm{~m}$ ) s'ouvre au nord, sur la partie ogivale, par des 


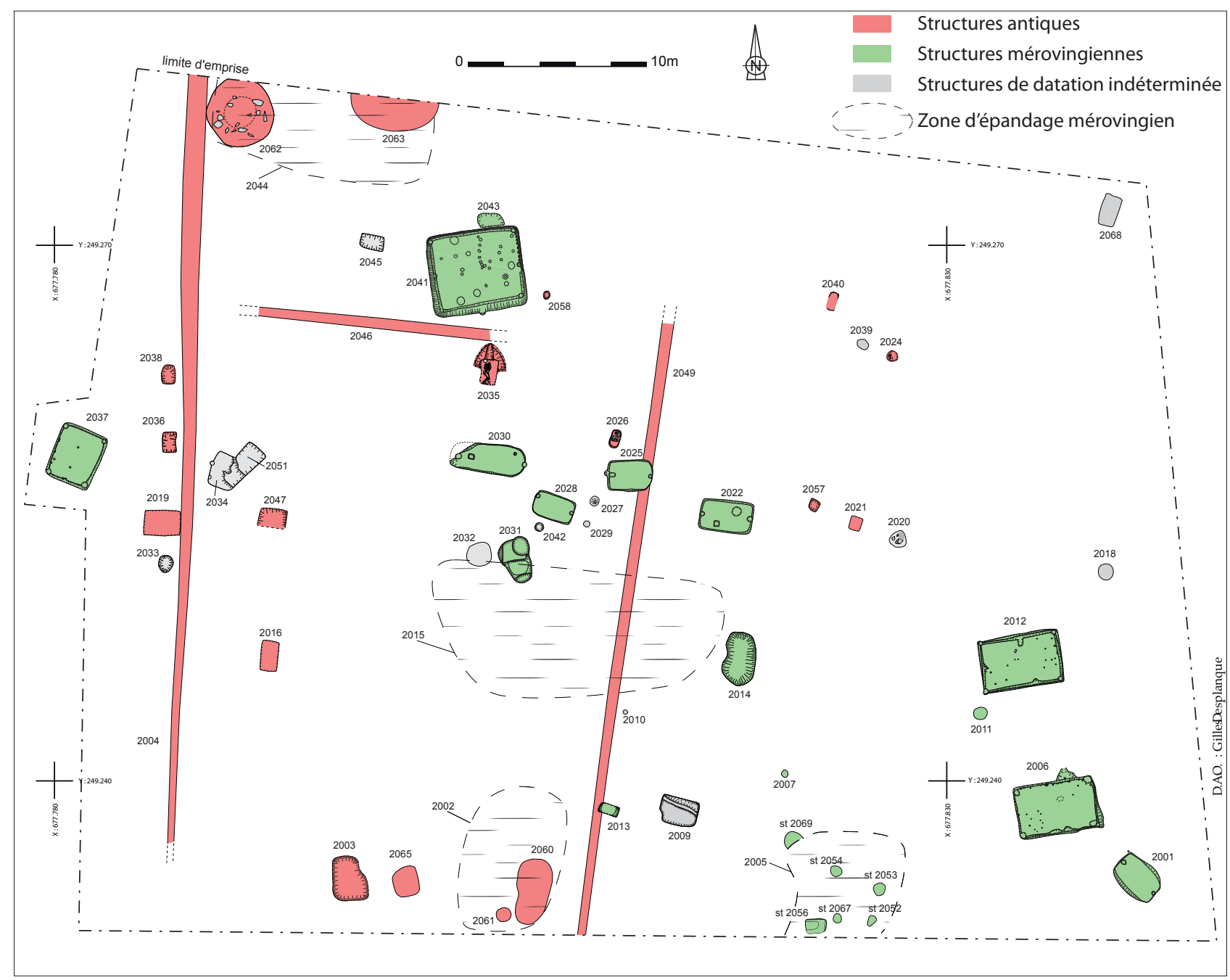

Fig. 2 - Plan du site.

parois évasées. La profondeur maximale conservée est de $70 \mathrm{~cm}$. Les membres inférieurs de l'individu ont été fléchis et sa tête repose en partie sur le bord évasé de la fosse. Des ossements appartenant à un autre individu ont été mis au jour dans le comblement sans qu'il soit possible de déterminer si la structure 2035 est une sépulture simple ou double. L'étude anthropologique, menée par William Devriendt (communauté d'agglomération du Douaisis, chercheur associé UMR 6578), a montré que le sujet principal est une femme de 40 à 45 ans, inhumée en pleine terre, en position de décubitus dorsal légèrement pivoté sur la gauche. Le second individu est un périnatal. La forme de la fosse invite peut-être à penser que cette structure n'a pas été initialement aménagée pour recevoir une inhumation. Un fragment d'objet métallique constitué de deux crochets en $U$ recourbés aux extrémités a été découvert aux pieds du squelette. Du mobilier céramique attribué au $\mathrm{I}^{\mathrm{er}}$ siècle après J.-C. était présent dans le comblement. Une datation par le radiocarbone à partir des os longs conduit à la fourchette chronologique 86-245 (Ly-14 791).

Faut-il conclure, de l'analyse de ces cinq sépultures, à une durée de vie sur un à deux siècles d'une petite nécropole familiale ? Dans ce schéma, l'absence de sépultures du II ${ }^{\mathrm{e}}$ siècle apparaîtrait comme étonnante. Compte tenu de la faible profondeur de conservation de ces structures, la disparition par arasement d'autres sépultures à crémation n'est pas à exclure.

\section{LES FOSSÉS 2004, 2049 ET 2046}

Les deux fossés parallèles 2004 et 2049, orientés nord/sud, sont distants de $24 \mathrm{~m}$. D'une largeur maximale de $1,2 \mathrm{~m}$, ils sont peu profonds $(40 \mathrm{~cm}$ maximum). Fortement arasé, le fossé 2046, d'une largeur équivalente, est perpendiculaire aux deux fossés 2004 et 2049. Ces trois fossés appartiennent probablement à un même parcellaire daté par le mobilier céramique du III ${ }^{\mathrm{e}}$ siècle.

\section{LES AUTRES STRUCTURES ATTRIBUÉES AU III ${ }^{\mathrm{e}} \mathrm{s}$.}

Trois foyers excavés de 1,50 à $2 \mathrm{~m}$ de long sur 1 à 1,40 m de large ont été étudiés (St 2016, 2047 et 2019). La présence de scories en calotte en position secondaire dans une section du fossé 2004 proche de ces structures interroge sur la fonction de ces foyers. 


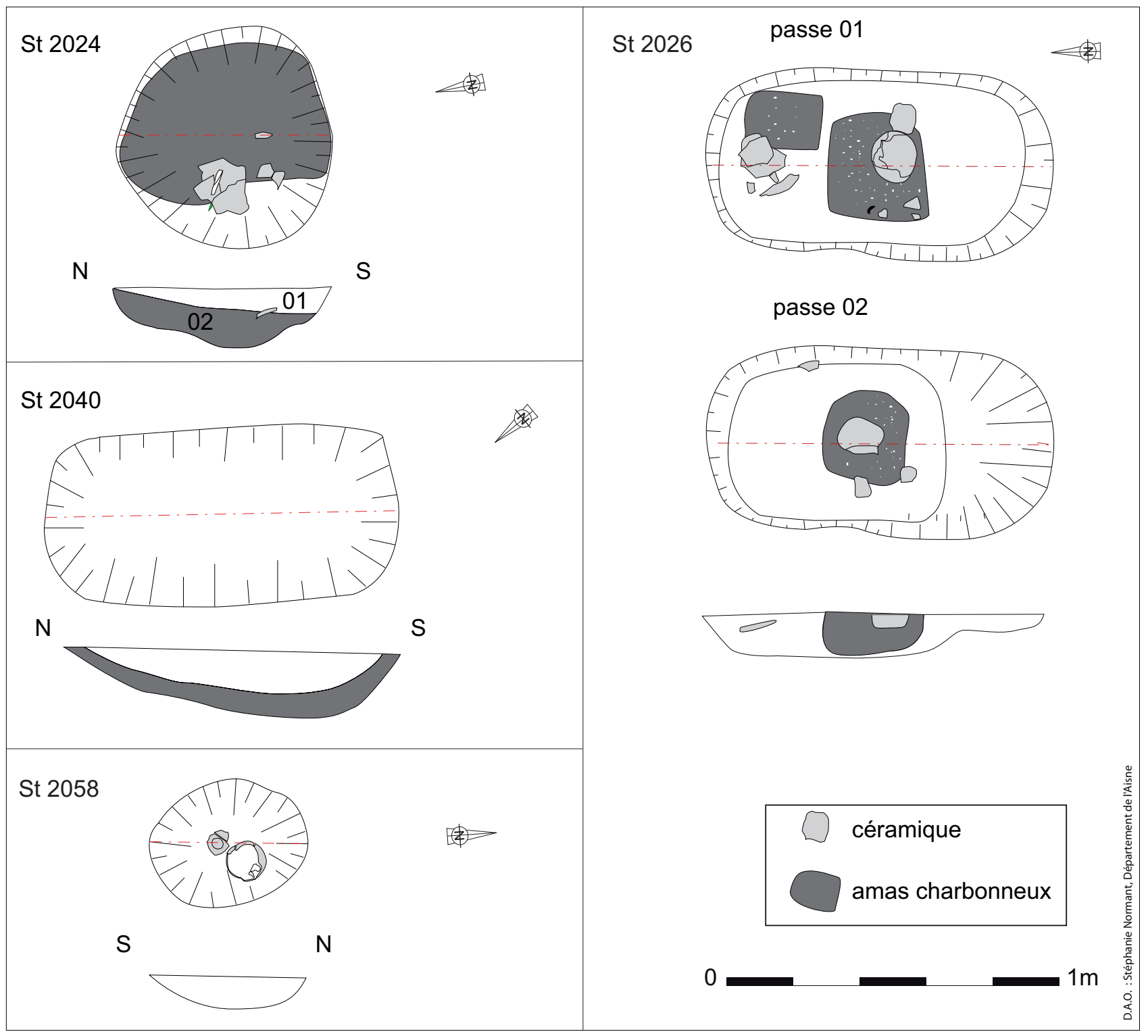

Fig. 3 - Les quatre incinérations 2026, 2024, 2040 et 2058.
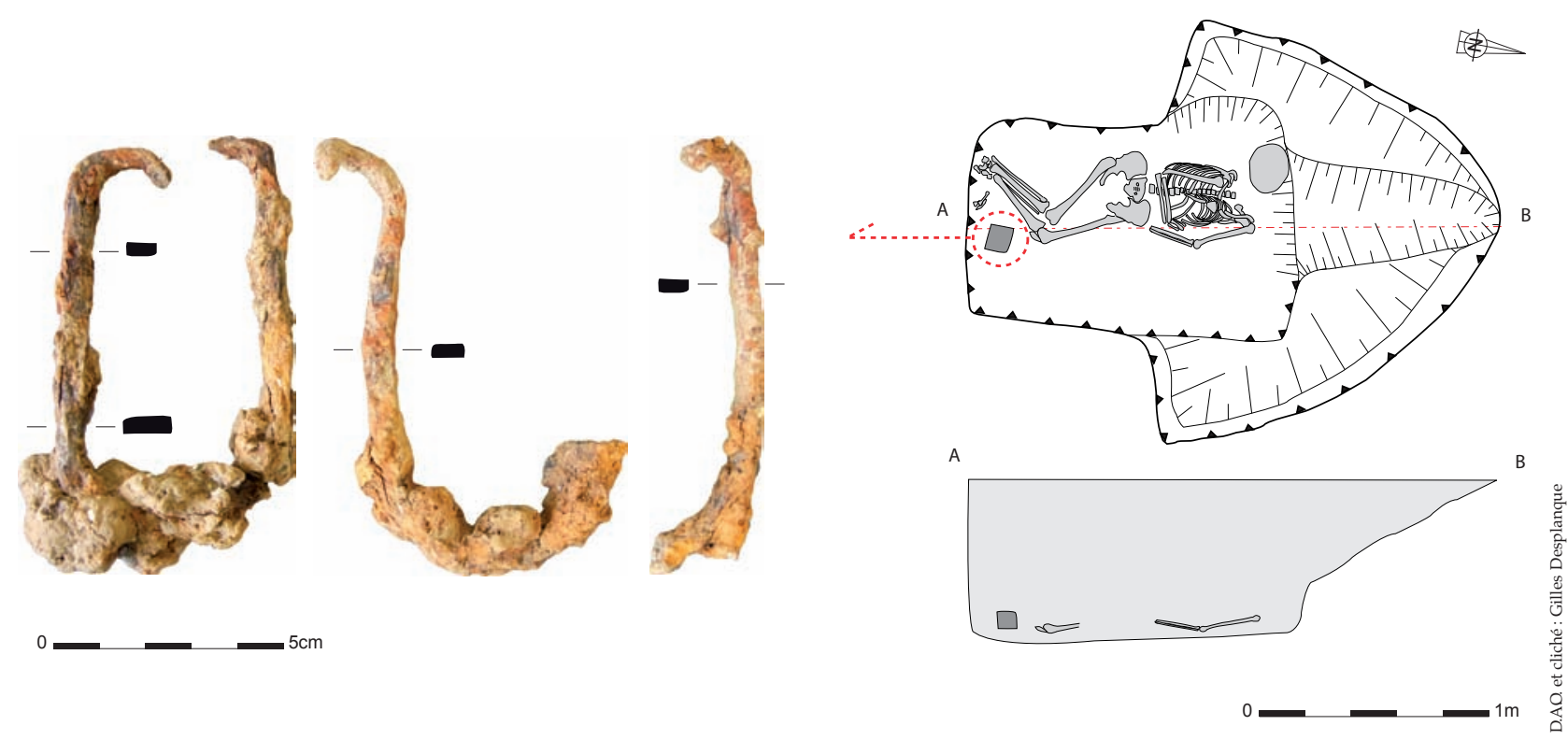

Fig. 4 - L'inhumation 2035. 


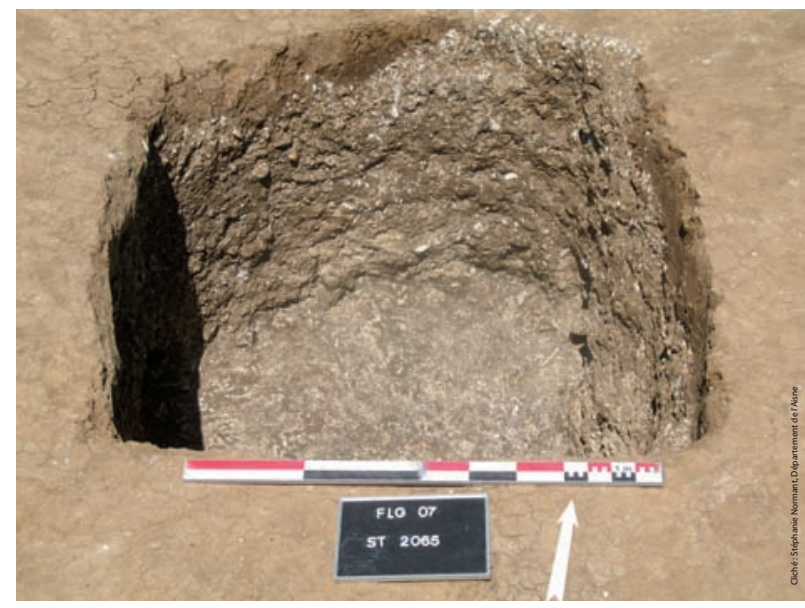

Fig. 5 - La structure 2065.

La structure 2065, de plan rectangulaire (longueur : 1,64 m, largeur : 1,53 m), est conservée sur une profondeur de 1,05 m (fig. 5). Ses bords sont verticaux et son fond est plat. L'argile limoneuse grise très charbonneuse qui la tapisse a été interprétée comme une couche d'occupation. Les caractéristiques de cette structure pourraient indiquer, avec prudence, un cellier.

Deux trous de poteau à section carrée 2021 et 2057 (60 à $70 \mathrm{~cm}$ de côté et $20 \mathrm{~cm}$ de profondeur) pourraient appartenir à une même structure de fonction indéterminée.

Enfin, un puits dont le conduit mesure 1,8 m de diamètre et dont la profondeur est supérieure à $9,5 \mathrm{~m}$ (St 2062), trois fosses d'extraction de matériau (St 2060, 2061 et 2063), une fosse-dépotoir (St 2003) et deux fosses de fonction indéterminée (St 2036 et 2038) ont également été datées de cette époque.

\section{LE MOBILIER ARCHÉOLOGIQUE}

Une pierre à aiguiser en grès verdâtre provient de la structure 2065 (fig. 6-1).

L'essentiel du mobilier en fer provient des structures 2003 et 2065 . Une clarine, une charnière de porte et trois pentures de coffre ont été mises au jour dans la première (fig. 6-10, 6-5, 6-11 à 6-13). Une autre clarine a été découverte dans la seconde (fig. 6-2).

Une plaque circulaire en alliage cuivreux de $5,5 \mathrm{~cm}$ de diamètre a été recueillie dans la fosse 2003 (fig. 6-6 à 6-9). Une de ses faces est lisse et l'autre est garnie de deux tétons diamétralement opposés. Cet objet, découvert à côté de trois rivets également en alliage cuivreux, appartenaient probablement à un harnachement de cheval.

Un fragment de fibule en alliage cuivreux, constitué par un ressort à quatre spires, a été mis au jour dans la structure 2035 (fig. 6-4). Son attribution chronologique est difficilement déterminable. Un autre fragment de fibule a été découvert dans la structure 2024 (fig. 6-3). Malgré son mauvais état de conservation, il est permis de l'apparenter à des types attestés dans le courant de la seconde moitié du I ${ }^{\text {er }}$ siècle après J.-C. (Feugere 1985, p. 182 et 183, types $14 b 1$ a et $23 a)$.

Les $256 \mathrm{~g}$ de scories recueillis dans la structure 2062 et dans la partie nord du fossé 2004 ont été identifiés par Vincent Le Quellec (département de l'Aisne) comme des scories de forge. Leur rejet dans ces structures invite à envisager la présence d'une forge en périphérie nord-ouest du site (FLUZIN BAUvaIs 2005, p. 120 et 121).

Avec seulement 16 restes fauniques déterminés sur un total de 25 livrés (pour un poids total de 257 g), le matériel issu des structures antiques est trop limité pour permettre une étude significative. Tout au plus pouvons-nous signaler que les vestiges identifiés appartiennent au bœuf, au porc, aux caprinés et au coq.

\section{La céramique gallo-romaine (A. CORSIEZ)}

Un total de 743 tessons dont 59 individus a été comptabilisé dans les 17 structures gallo-romaines qui contenaient de la céramique (1). Le matériel s'est révélé fragmenté et les surfaces usées, voire rongées par le sédiment, ce qui a rendu parfois difficile l'attribution à une catégorie précise. Dix catégories ont été reconnues et peu de types identifiés. Les individus en céramique commune sombre ou claire ainsi que ceux en céramique fine régionale sont nommés selon la typologie mise en place dans le cadre des études céramologiques gallo-romaines du Pôle archéologique du Département de l'Aisne et sont précédés de l'abréviation « Aisne».

\section{Les catégories (2) et la typologie}

La terre sigillée (TS) et les imitations de terre sigillée (ITS) : cinq tessons dont deux individus ont été attribués à la terre sigillée. Le seul type qui a pu être identifié est une bouteille Déchelette 65 provenant d'Argonne.

1 - La céramique est inventoriée après recollage, le nombre minimum d'individus est déterminé à partir des lèvres d'individus différenciés. Les pâtes et surfaces des tessons qui ont été isolés pour être dessinés, ont été décrites, regardées à la loupe binoculaire (grossissement x 20) pour déterminer des groupes de pâtes. Les couleurs sont choisies selon le guide philatélique des couleurs Michel. Les identifications des pâtes ont été faites dans le laboratoire de céramologie de l'université Lille3, HalmaIpel 8164 .

2 - Les catégories sont définies à partir de trois critères: le critère technologique qui tient compte du façonnage, de la cuisson et de l'aspect de la surface ; le critère typologique, c'est-à-dire un faciès général commun et le critère fonctionnel. 


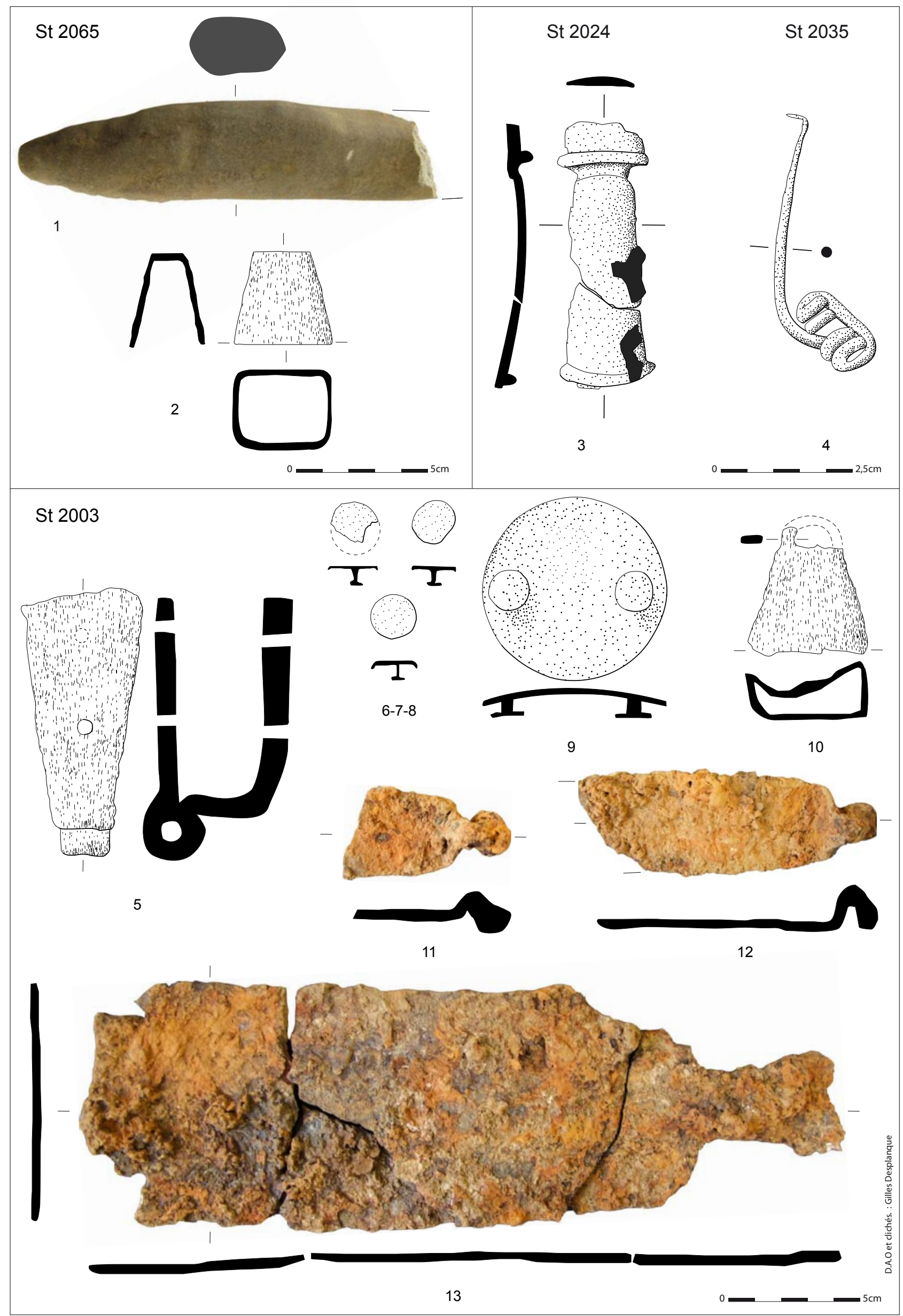

Fig. 6 - Le mobilier romain non céramique. 


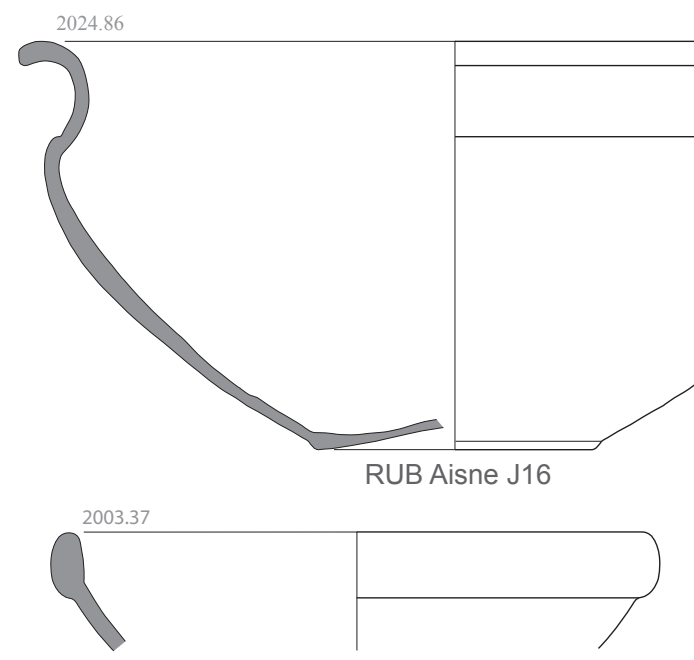

RUB Aisne J5

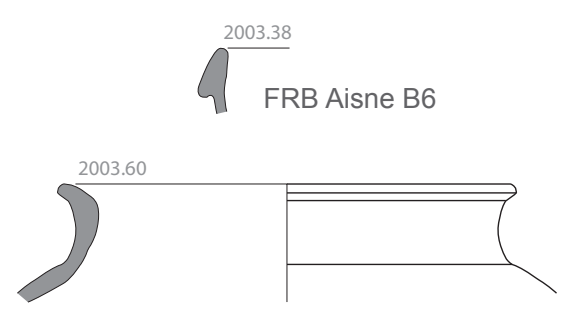

RUB Aisne P1

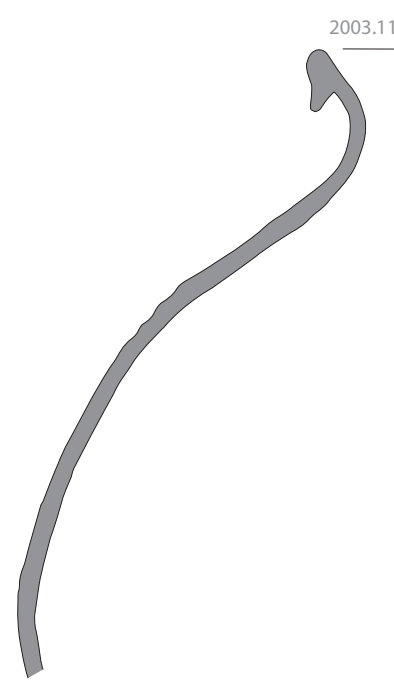

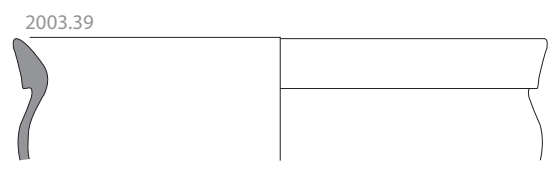

RUB Aisne J28

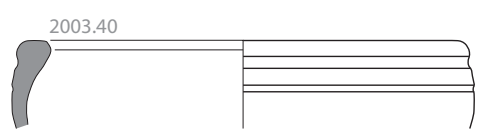

RUB Aisne J10

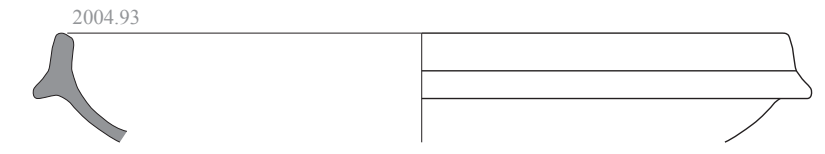

RUB Aisne A12
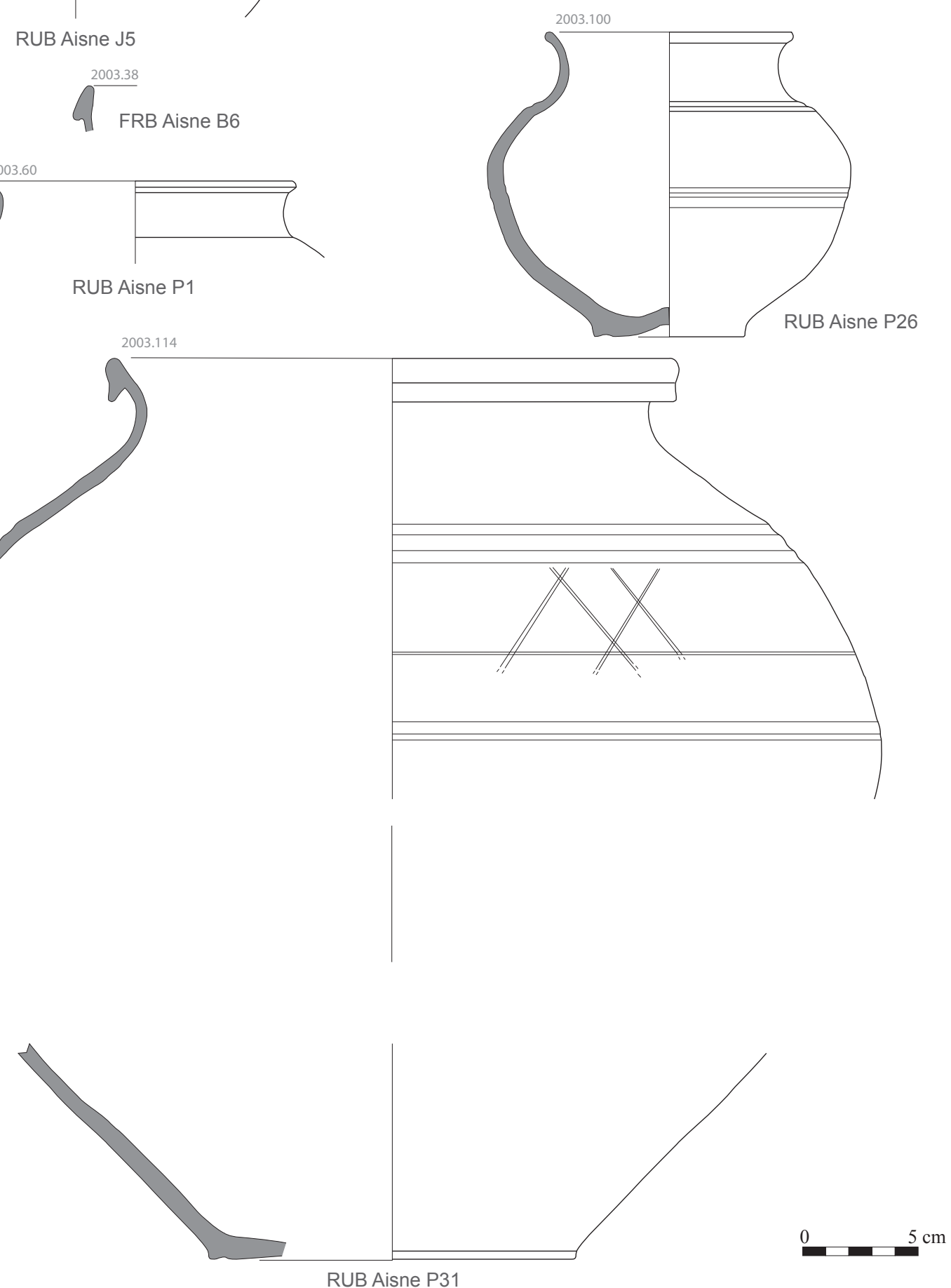

Fig. 7 - Planche typologique : A. La céramique rugueuse (RUB) et fine (FRB) antique (éch. : 1/3, dessin et DAO A. CORSIEZ). 
Les imitations de sigillée sont plus abondantes avec 24 tessons dont trois individus. Il s'agit d'une catégorie que l'on rencontre régulièrement au $\mathrm{IV}^{\mathrm{e}}$ et épisodiquement au $\mathrm{III}^{\mathrm{e}} \mathrm{s}$. ; les formes du $\mathrm{IV}^{\mathrm{e}} \mathrm{s}$. imitent les standards tardifs de la sigillée, notamment les Chenet 320 et les Drag 45. Ici, la seule forme attestée est le bol à collerette Drag 38. Ne sont pas présents les marqueurs chronologiques fiables comme les molettes sur Chenet 320 qui indiqueraient une datation au IV $\mathrm{s}$. Deux groupes de pâte ont été repérés.

La terra nigra (TN) : la seule forme identifiée est un P54, fabriqué dès les années 40 jusqu'au début $\mathrm{du} \mathrm{II}^{\mathrm{e}}$ s. Il provient de l'atelier des Rues-des-Vignes dans le Cambrésis. Un fragment d'assiette provient des ateliers champenois. Seuls 13 tessons dont un individu ont pu être rattachés à cette catégorie.

La céramique fine régionale sombre (FRB) : 43 tessons dont cinq individus appartiennent à la fine régionale. Deux formes ont été identifiées : un bol hémisphérique à lèvre en crochet (Aisne B1) et un bol à lèvre en collerette (Aisne B6). Le bol Aisne B1 a été attribué au groupe de pâte $C$, correspondant aux ateliers de la sphère Vermand/St-Quentin (3).

La céramique à vernis rouge pompéien (VRP) : les trois assiettes de cette catégorie proviennent de l'atelier des Rues-des-Vignes (4), actif du milieu du $\mathrm{II}^{\mathrm{e}} \mathrm{s}$. à la fin du $\mathrm{III}^{\mathrm{e}} \mathrm{s}$.

La céramique rugueuse sombre (RUB) : cette catégorie est, commesouvent, la plus abondante avec 286 tessons dont 33 individus. Le pot à col concave Aisne P1 est le plus abondant (3 individus). C'est le type caractéristique de la cité des Viromanduens du $\mathrm{I}^{\mathrm{er}}$ au $\mathrm{III}^{\mathrm{e}} \mathrm{s}$. mais on le retrouve également dans la cité des Nerviens sous l'appellation M1 (CLOTUCHE \& Willems 2007) pour la même période. Un exemplaire est fabriqué en pâte B (5) des ateliers du Saint-Quentinois ainsi que la jatte Aisne J5, datée par Stéphane Dubois du milieu du $\mathrm{I}^{\mathrm{er}}$ au $\mathrm{II}^{\mathrm{e}} \mathrm{s}$. (DuboIs \& BOURSON 2001). Le pot Aisne P31 est fabriqué dans une pâte à quartz septentrionale. La jatte Aisne J28 est datée par les auteurs précédents du $2^{\mathrm{e}}$ quart du $\mathrm{II}^{\mathrm{e}}$ s. au $3^{\mathrm{e}}$ quart du III' s. (fig. 7).

La céramique commune claire (CC) : parmi les 222 tessons dont cinq individus, les groupes de pâte noyonnais et savonneux ont été identifiées.

3 - Tous les groupes de pâtes identifiés par une lettre de l'alphabet selon leur catégorie ont été établis dans le cadre des études céramiques du pôle archéologique du Département de l'Aisne. Pour la description du groupe C de la FRB, se reporter à l'article CoRsiez 2008.

4 - Pour la description des pâtes se référer à l'article de Xavier Deru (DeRU 2005).

5 - Les groupes de pâtes de la RUB ont été précédemment décrits dans l'article CORSIEZ 2008.
Le dolium (DO) : un groupe de pâte présente des caractéristiques proches des productions de l'atelier des Rues-des-Vignes. Cette catégorie comptabilise 76 tessons dont un individu.

Les amphores (AM) : sur quatre tessons, trois proviennent de Narbonnaise et un de Bétique.

\section{Esquisse de datation et conclusion}

Peu de structures ont pu être datées avec certitude. À l'exception de la structure 2024, datée de la deuxième moitié $d u$ I ${ }^{\text {er }}$ siècle au début du II ${ }^{\mathrm{e}}$ siècle grâce au TN P54, les comparaisons ont montré que la majorité des comblements gallo-romains pouvaient être circonscrits chronologiquement au $\mathrm{III}^{\mathrm{e}}$ siècle, malgré l'absence du fossile directeur caractéristique qu'est la métallescente. Cette datation bien que peu étayée semble néanmoins la plus plausible. Les types qui ont pu être identifiés dans les catégories de céramique commune montrent un faciès propre à la cité des Viromanduens avec quelques importations (VRP, TN) du Sud de la cité des Nerviens.

\section{Catalogue de la structure 2003}

Il s'agit de la structure contenant le plus de céramique avec 537 tessons (72\% du total) dont 41 individus. La céramique rugueuse présente est en usage du ${ }^{\mathrm{I} r}$ au $\mathrm{III}^{\mathrm{e}}$ s. : Aisne P1, Aisne J28 et Aisne J5 l'attestent. En revanche, la céramique fine semble plus tardive : imitation de terre sigillée avec un Drag 38, terre sigillée d'Argonne : peut-être du III ${ }^{\mathrm{e}} \mathrm{s}$. ou déjà du IV e s., malgré l'absence de Chenet 320. La céramique à vernis rouge pompéien indique également une datation dans le III ${ }^{\mathrm{e}}$ s. (fig. 8).

1. TS ARG DECH.65 : bord conservé à $100 \%$; S à engobe orange rouge sombre ; $\mathrm{P}$ orange sombre, fine; ø interne : $2 \mathrm{~cm}$.

2. FRB B Aisne $\mathrm{B} 6$ : bord conservé à $5 \%$; $\mathrm{S}$ grise, lisse ; $\mathrm{P}$ grise, fine ; $\varnothing$ : env. $17 \mathrm{~cm}$.

3. RUB B Aisne J5 : bord conservé à $10 \%$; S lisse, gris noir ; $\mathrm{P}$ à noyau brun jaune sombre et frange noire ; ø : $18 \mathrm{~cm}$.

4. RUB C Aisne J10 : bord conservé à $10 \%$; S gris orangé à gris noir, rugueuse $\mathrm{P}$ à noyau gris sombre et franges gris noirâtre; $\varnothing: 13 \mathrm{~cm}$.

5. RUB Aisne J28 : bord conservé à $10 \%$; S rugueuse, abîmée, gris jaune clair à gris ; $\mathrm{P}$ brun gris clair ; ø : $18 \mathrm{~cm}$.

6. RUB D Aisne P1 : bord conservé à $15 \%$; S rugueuse gris à gris vif; $\mathrm{P}$ gris mat ; $\varnothing: 14 \mathrm{~cm}$.

7. RUB SEPT Aisne P1 : bord conservé à $60 \%$; S rugueuse, gris sombre, le fond est bruni par le feu ; P grise ; $\varnothing: 10,7 \mathrm{~cm}$.

8. RUB SEPT Aisne P31 : bord conservé à $30 \%$; S rugueuse à lisse, gris vif ; $\mathrm{P}$ gris sombre, feuilletée ; D. $25 \mathrm{~cm}$, D. fond : $16 \mathrm{~cm}$.

9. RUB Indét. : $S$ rugueuse, noir gris, zone brun jaune sombre ; P noir gris, comportant de nombreux minéraux de gros calibre, du silex. 
RAP - 2010, n 1/2, Thierry Galmiche, Gilles Desplanque et al., L'habitat rural mérovingien de Fresnoy-le-Grand (Aisne) "Les Champs à Grès".
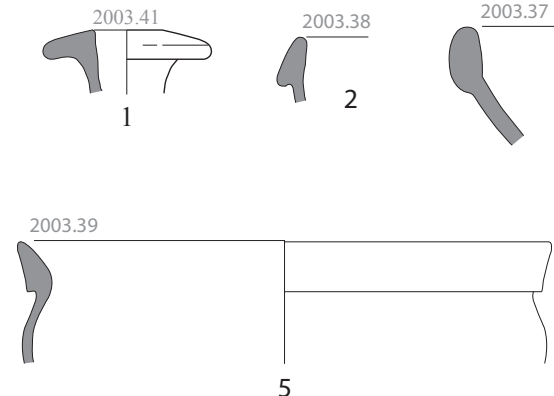

5

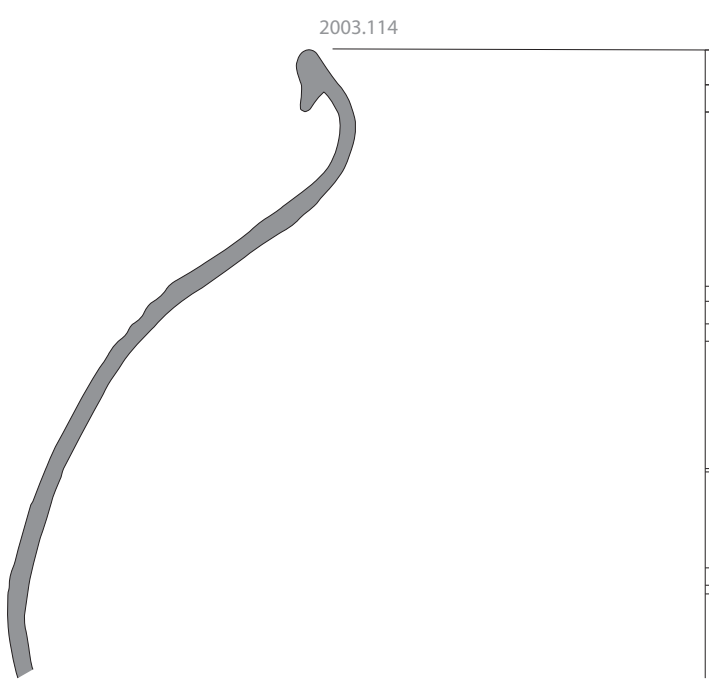

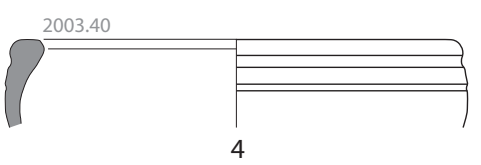

4
3

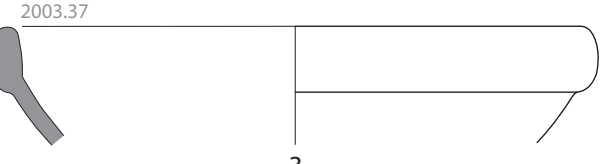

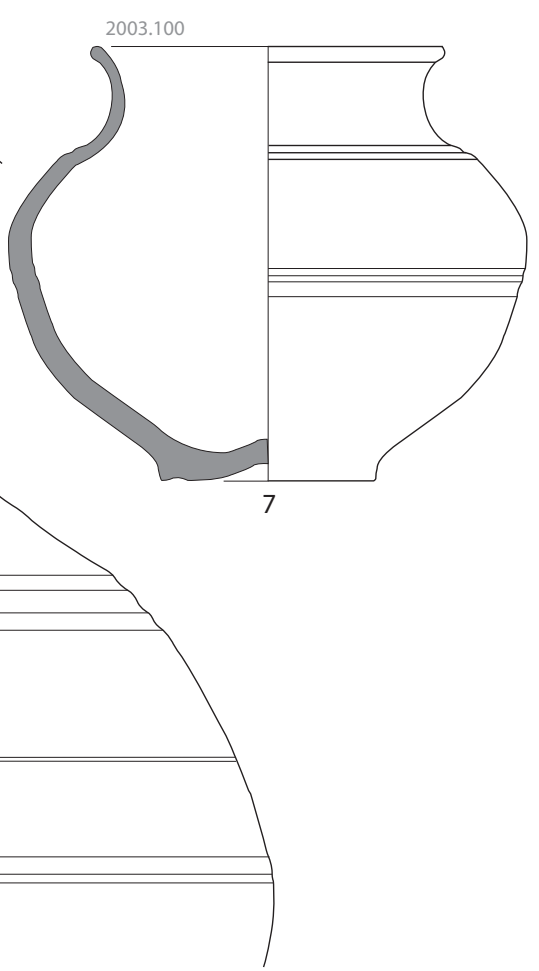
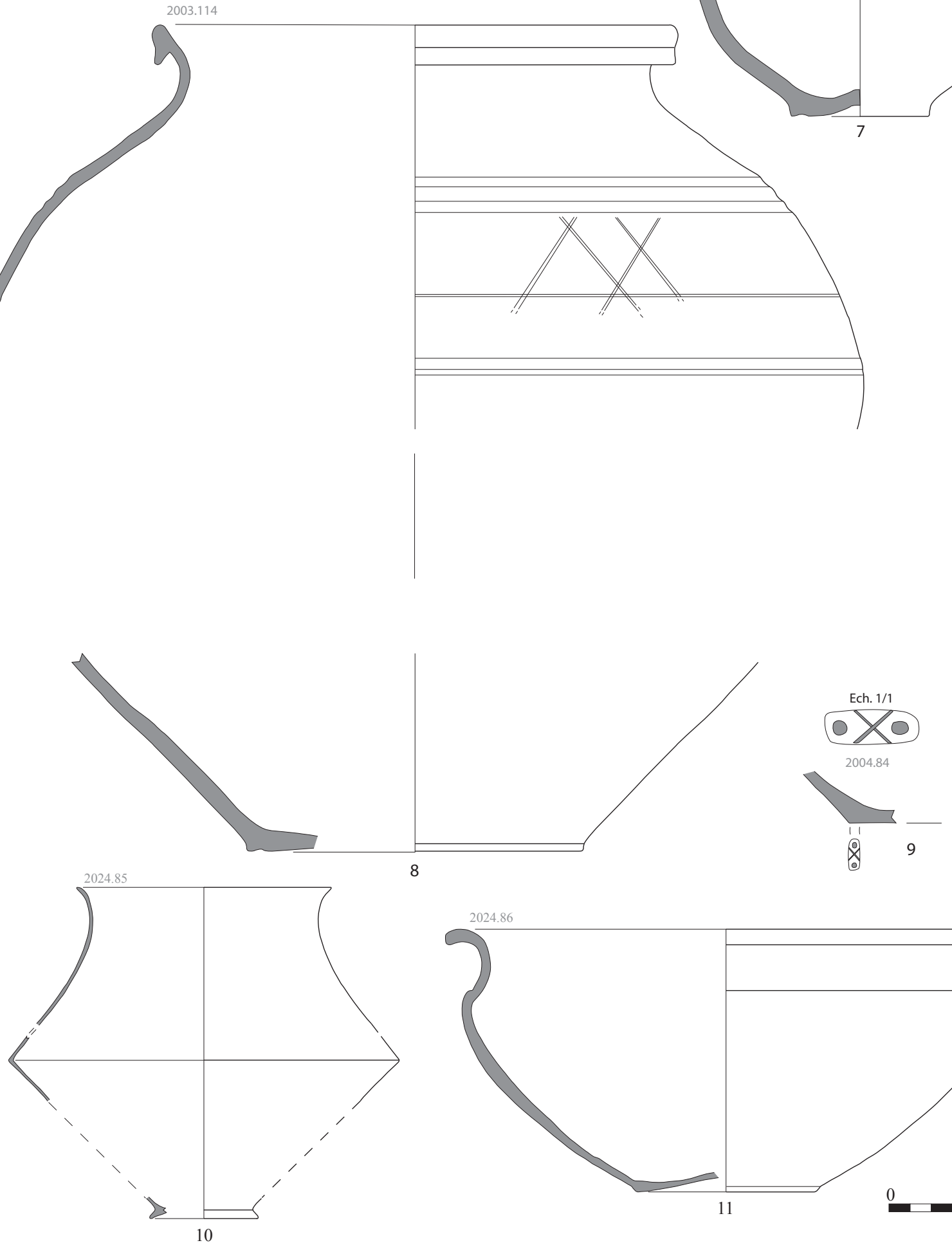

8
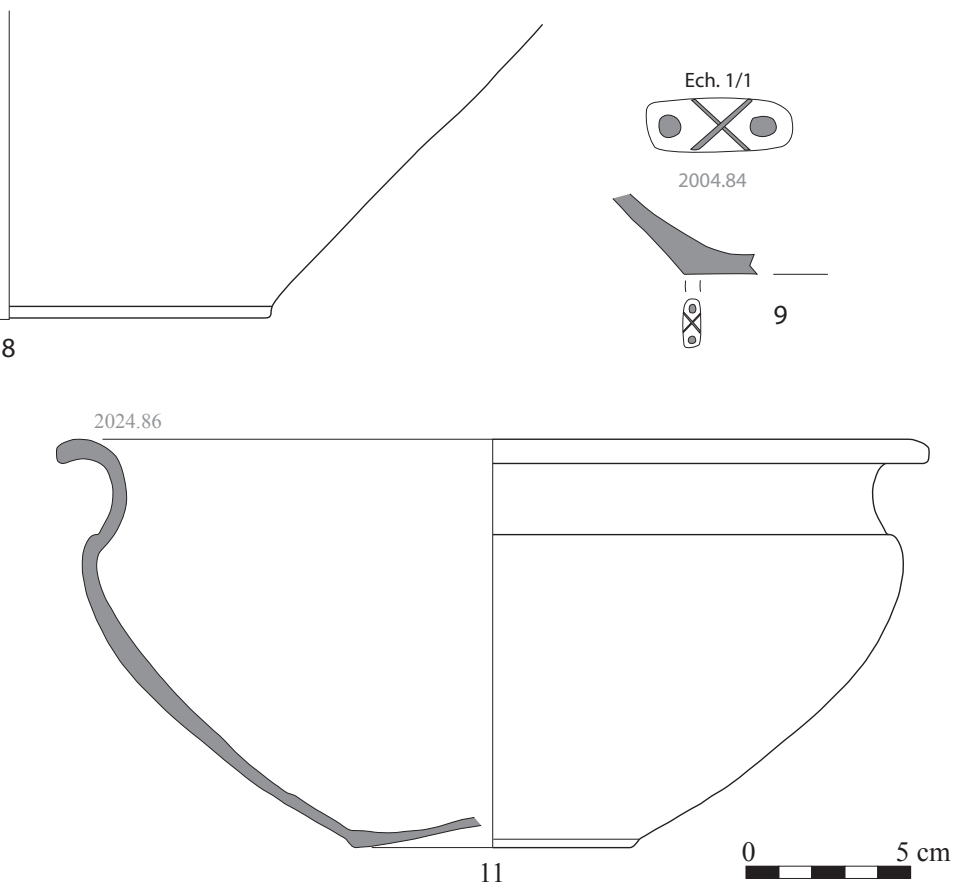

Fig. 8 - Céramique des structures 2006, 2037, 2014 et 2022, (éch. 1/3, dessin et DAO A. CORSIEZ).

202 
10. TNo RDVB P54 : estampille sur le fond, IIIAIIO ; bord conservé à $20 \%$; S abîmée, jaune chrome clair ; $\mathrm{P}$ à noyau noir gris et fines franges jaune chrome clair ; $\varnothing: 12 \mathrm{~cm}$.

11. CC ? C ? RUB T2 : bord conservé à $12 \%$; S ocre brun clair, rugueuse ; $\mathrm{P}$ à noyau gris sombre à gris noir et fines franges ocre brun clair ; $\varnothing: 26,6 \mathrm{~cm}$.

Les vestiges fouillés ainsi que le mobilier afférant révèlent une occupation qui pourrait être implantée en périphérie d'une exploitation agricole du $\mathrm{III}^{\mathrm{e}} \mathrm{s}$. Des quantités relativement abondantes de scories attestent la présence d'une forge au nord-ouest de l'emprise de la fouille, tandis qu'une structure, interprétée avec prudence comme un cellier (St 2065), indique peut-être la limite nord des premières constructions. Les quatre sépultures à incinération et la sépulture à inhumation pourraient appartenir à une petite nécropole familiale liée à l'ensemble agricole. Si l'incinération la plus récente date du III ${ }^{e}$ s., la plus ancienne est de la fin du Ir $\mathrm{e}$. Cet indice pourrait plaider pour une occupation précoce de ce site.

\section{L'OCCUPATION MÉROVINGIENNE}

\section{LES FONDS DE CABANE ET LE BÂTIMENT EXCAVÉ}

Huit fonds de cabane et un bâtiment excavé de plus grande superficie ont été attribués à la période mérovingienne (fig. 9). Ils peuvent être classés en trois types en fonction de leur superficie, du nombre de poteaux soutenant la charpente et du mode de construction de leurs parois (tab. I).

Le bâtiment excavé 2041 (fig. 10) repose sur quatre poteaux corniers et deux poteaux placés au milieu des petits côtés. Les poteaux corniers constituent l'ossature du bâtiment excavé et supportent les sablières hautes et les entraits. Les poteaux médians sont de plus petite taille et moins profondément enfoncés que les précédents. Deux possibilités de restitution peuvent être proposées : soit ces derniers poteaux servaient de relais dans le maintien des sablières, soit ils étaient employés pour supporter la panne faîtière. Même si les deux

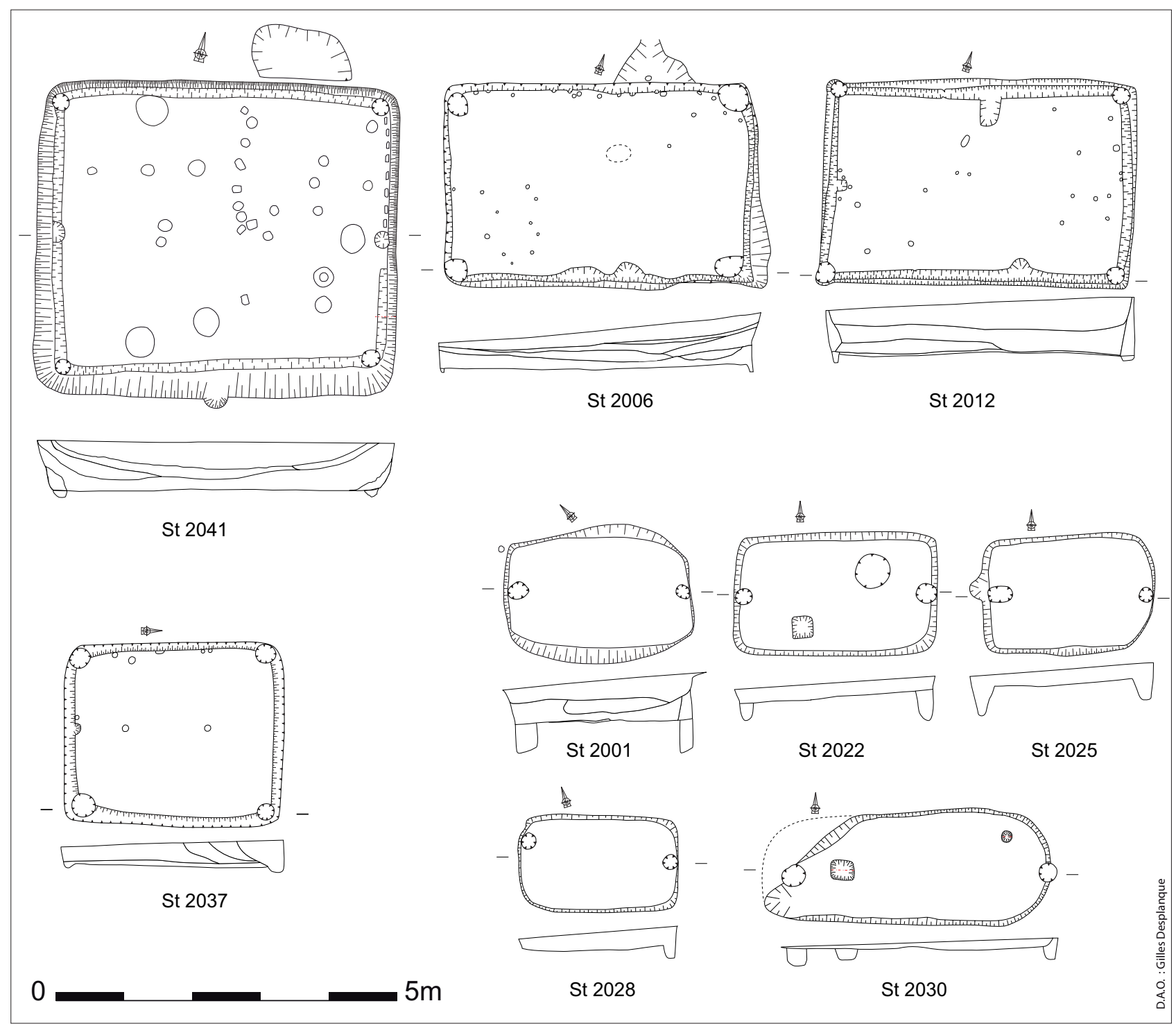

Fig. 9 - Le bâtiment excavé 2041 et les huit fonds de cabane 2006, 2012, 2037, 2001, 2022, 2025, 2028 et 2030. 


\begin{tabular}{|l|c|c|c|c|c|c|c|c|c|}
\hline$N^{\circ}$ de structure & 2041 & 2006 & 2012 & 2037 & 2001 & 2022 & 2025 & 2028 & 2030 \\
\hline Longueur moyenne à l'ouverture & 4,8 & 4,46 & 4,4 & 3,08 & 2,66 & 2,91 & 2,48 & 2,32 & 4 \\
\hline Largeur moyenne à l'ouverture & 4,05 & 2,8 & 2,77 & 2,58 & 1,81 & 1,72 & 1,68 & 1,38 & 1,58 \\
\hline Profondeur moyenne & 0,71 & 0,55 & 0,72 & 0,35 & 0,59 & 0,2 & 0,2 & 0,24 & 0,09 \\
\hline Superficie utile $\left(\mathrm{m}^{2}\right)$ & 18,4 & 11,2 & 10,5 & 7,1 & 4,2 & 4,6 & 3,8 & 3 & 5,6 \\
\hline Longueur / largeur & 1,21 & 1,66 & 1,68 & 1,2 & 1,62 & 1,74 & 1,52 & 1,74 & 2,49 \\
\hline Nombre de poteaux porteurs & 6 & 4 & 4 & 4 & 2 & 2 & 2 & 2 & 2 \\
\hline Présence d'une tranchée périphérique & oui & oui & oui & oui & non & non & non & non & non \\
\hline Présence de piquets & oui & oui & oui & oui & non & non & non & non & non \\
\hline
\end{tabular}

Tab. I - Descriptif du bâtiment excavé et des fonds de cabane.

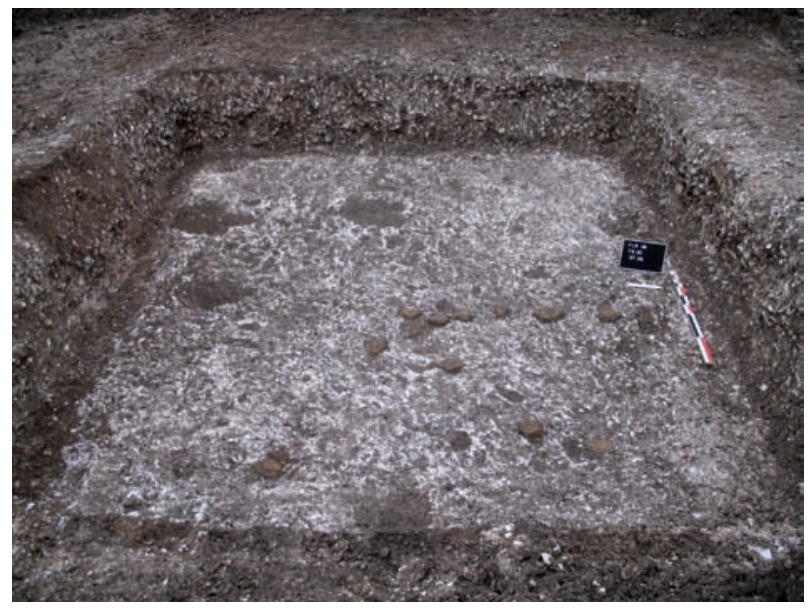

Fig. 10 - Le bâtiment excavé 2041.

schémas sont envisageables (GentiLI, EpAux, Simard 2009, p. 137), il semble plus probable, au vu des vents dominants et de l'orientation générale des autres cabanes sur ce site, de privilégier le seconde possibilité. Une tranchée étroite court le long des quatre parois à l'exception de la moitié nord du côté oriental. Elle peut être interprétée comme le vestige de l'ancrage d'une cloison (Peytremann 2003, vol. 1, p. 275). La position relative des six poteaux porteurs par rapport à cette tranchée permet d'envisager une cloison sur sablière basse. La présence de nombreux fragments de torchis dans les niveaux de démolition du bâtiment tend à confirmer cette hypothèse. La cloison s'interrompt sur le bord oriental pour laisser place à une rangée de huit trous de piquet de section rectangulaire. Ces piquets, consistant en des rondins équarris dans le sens de la longueur, participaient à un aménagement qui permettait l'accès au bâtiment. Deux trous de poteaux placés en ligne parallèlement au bord nord de la cabane complétaient ce dispositif. La fonction de la fosse St 2043 mise au jour immédiatement au nord reste indéterminée. La fouille stratigraphique indique clairement un creusement indépendant et non un surcreusement de la paroi du bâtiment excavé. Aussi semble-t-il difficile d'y reconnaître un aménagement lié à l'accès tel que documenté sur d'autres sites (GENTILI 2009, p. 34). Des trous de piquet et des zones circulaires de 12 à $15 \mathrm{~cm}$ de diamètre matérialisent la présence d'aménagements intérieurs tels que des cloisons, des supports de stockage ou d'autres éléments liés à une activité artisanale.

La charpente des trois fonds de cabane 2006, 2012 et 2037 repose sur quatre poteaux corniers (fig. 11). Une tranchée de 5 à $15 \mathrm{~cm}$ de large et d'une dizaine de centimètres de profondeur a été aménagée le long des parois. Elle permet d'ancrer la paroi probablement au moyen d'une sablière basse. Des creusements de faible importance $(4$ à $10 \mathrm{~cm}$ de diamètre pour une profondeur de $5 \mathrm{~cm}$ ) ont été mis en évidence dans le fond de ces structures. Ils peuvent être interprétés comme des vestiges d'aménagements intérieurs difficiles à restituer : cloisons, supports... La présence d'un creusement au nord du fond de cabane 2006 interroge. Faut-il y voir un aménagement pour l'accès ? La fouille stratigraphique ne l'exclut pas. Les dimensions des deux cabanes 2006 et 2012, parallèles entre elles, sont pratiquement identiques. Ces similitudes ne sont pas fortuites. Plusieurs hypothèses peuvent être proposées : simultanéité dans la construction, complémentarité dans la destination de chacune d'elle ou activité dont l'importance aurait nécessité le recours à deux cabanes de fonction identique.

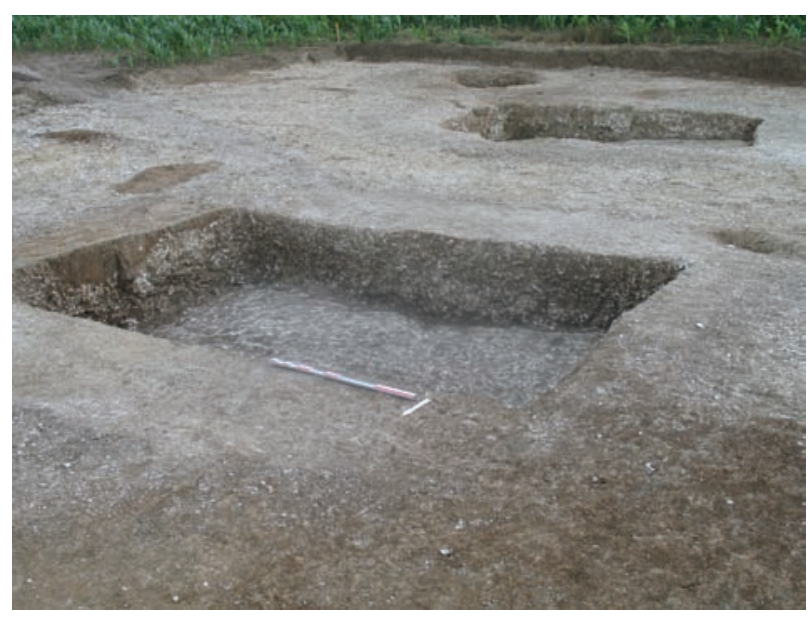

Fig. 11 - Les fonds de cabane 2012, 2006 et 2001. 


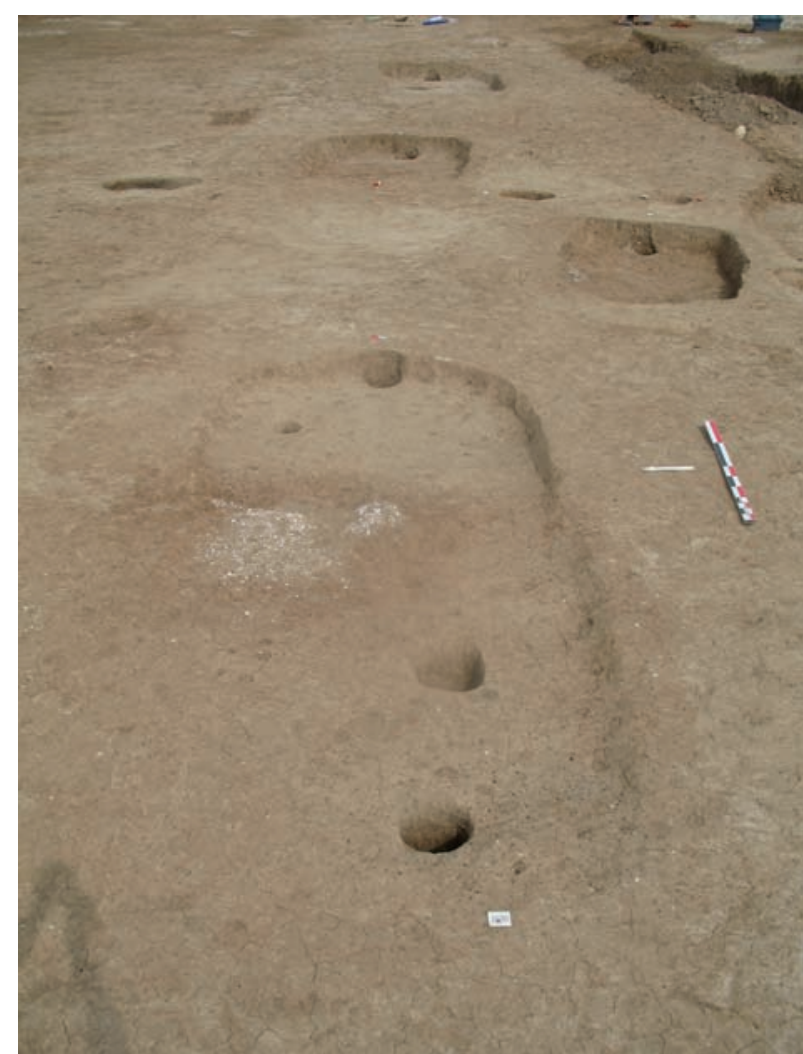

Fig. 12 - Les fonds de cabane 2022, 2025, 2028 et 2030.

Les cabanes à deux poteaux faîtiers placés au milieu des petits côtés (St 2001, 2022, 2025, 2028 et 2030) sont de surface plus restreinte (fig. 12). Deux creusements ont été aperçus à l'intérieur des cabanes 2022 et 2030. Étant donné le diamètre important $(52 \mathrm{~cm}$ ) de celui de la structure 2022, il pourrait avoir été aménagé comme base pour un billot. Mis à part ces creusements, aucun aménagement n'a été mis en évidence dans ces structures. La faible superficie des cabanes 2022, 2025, 2028 et 2030 pourrait inviter à les interpréter comme des ateliers réunis, par commodité, sur une même zone. La présence de trous de poteau de datation indéterminée à proximité de la cabane 2028 plaide peut-être pour la présence à cet endroit d'un aménagement lié aux cabanes : palissade ou support d'installation artisanale (structures 2027, 2029 et 2042).

L'essentiel du mobilier a été prélevé dans les couches de remblai postérieures à l'abandon de ces structures. L'examen de la céramique n'a pas montré de différences chronologiques entre les différentes unités stratigraphiques qui constituent ce comblement. Ce mobilier est attribué à une période comprise entre la seconde moitié du $\mathrm{VI}^{\mathrm{e}} \mathrm{s}$. et la seconde moitié du VII ${ }^{\mathrm{e}} \mathrm{s}$. La présence dans le remplissage des fonds de cabane 2022 et 2001 de tessons de céramiques attribués à la seconde moitié du VII ${ }^{\text {s., }}$ voire au début du VIII ${ }^{\text {e }}$ s., invite peutêtre à envisager que ces structures sont légèrement postérieures. Ces constructions auraient, ainsi, pu succéder à une construction voisine. En l'absence de relations stratigraphiques et compte tenu du fait que la datation repose sur du mobilier découvert dans des couches de comblement, il convient de rester prudent.

Le plan des cabanes et du bâtiment excavé découverts à Fresnoy-le-Grand est systématiquement rectangulaire. Leur superficie est assez variable $\left(3\right.$ à $\left.17 \mathrm{~m}^{2}\right)$ pour une moyenne de $7,6 \mathrm{~m}^{2}$, valeur comparable à celles mesurées en Île-deFrance pour la période mérovingienne (Deschamp 2009 , p. 64). Le ratio moyen longueur sur largeur s'établit à 1,65, valeur analogue à ce qui a été calculé à Villiers-le-Sec dans le Val-d'Oise (GentiLi 2009, p. 33). Mise à part la cabane 2030 très allongée, la longueur n'excède pas 1,8 fois la largeur. Parmi les neuf bâtiments excavés découverts, cinq possèdent deux poteaux. Cette proportion est beaucoup moins importante que celle mesurée à Villiers-le-Sec (Vald'Oise), pour la fin de la période mérovingienne : $84 \%$ (Gentili 2009, p. 34). Pour les Ve et VI ${ }^{\mathrm{e}}$ s., cet auteur insiste sur une plus grande représentation du type à poteaux corniers pour des sites géographiquement proches. La répartition par dispositif de couverture à Fresnoy-le-Grand entre la seconde moitié du $\mathrm{VI}^{\mathrm{e}}$ et le début du VIII ${ }^{\mathrm{e}} \mathrm{s}$. apparaîtrait donc peu différente de ce qui a été observé dans le Nord de l'Île-de-France. Compte tenu de la faiblesse de notre échantillon statistique, il convient cependant de rester prudent quant à la représentativité de ces chiffres. L'orientation des trois cabanes ou bâtiments excavés les plus vastes est identique. Celle des quatre cabanes 2022, 2020, 2025 et 2030, relativement semblable, reste globalement est/ ouest. Les deux cabanes 2037 et 2001 apparaissent, en revanche, relativement désaxées. Un niveau de sol, d'épaisseur inférieure à $2 \mathrm{~cm}$, a été identifié pour les structures 2041, 2012 et 2037. Pour les autres cabanes, l'interface entre le substrat et le premier niveau de comblement, parfois légèrement indurée, indique un piétinement. Aucun reste carpologique n'a été découvert après tamisage des sédiments prélevés dans ces niveaux de sol ou de piétinement. Aucune battiture n'a été ramassée dans ces prélèvements. Au vu de cet élément, l'identification de ces cabanes comme des forges semble exclue. La localisation des creusements internes interdit également de les interpréter comme des lieux de tissage. Les possibilités le plus souvent proposées quant à la fonction de ces structures excavées peuvent être avancées : resserre, atelier, lieu de stockage, bergerie voire habitation dans le cas du bâtiment le plus vaste (Peytremann 2003, vol. 1, p. 279).

\section{UNE PRÉSOMPTION DE BÂTIMENT}

SUR POTEAUX (les trous de poteaux 2052, 2053, 2054 et 2067)

À l'ouest de la cabane 2006, le décapage d'une couche d'épandage de quelques centimètres d'épaisseur (structure 2005) a mis en évidence quatre trous de poteau circulaires 2052, 2053, 2054 
et 2067. Leur diamètre est compris entre 50 et $70 \mathrm{~cm}$ et leur profondeur varie entre 20 et $50 \mathrm{~cm}$. Ces quatre poteaux participent peut-être à la charpente d'un bâtiment qui pourrait se prolonger vers le sud en dehors de l'emprise de l'opération. Le niveau d'épandage 2005 serait peut-être relatif à la destruction de ce bâtiment.

Les deux structures de combustion 2056 et 2069 étaient également scellées par le niveau d'épandage 2005. La première, de plan rectangulaire (longueur : $1,16 \mathrm{~m}$, largeur : 0,80 m), présente une sole rubéfiée d'une épaisseur de neuf centimètres. La seconde était en grande partie arasée.

Ces deux foyers étaient peut-être en lien avec l'hypothétique bâtiment sur poteaux.

\section{LES AUTRES STRUCTURES MÉROVINGIENNES}

Trois niveaux d'épandage (St 2015, 2044 et 2002), d'une superficie comprise entre 50 et $100 \mathrm{~m}^{2}$, scellent des structures antiques. Ils consistent en un niveau de limon brun qui s'affine vers l'extérieur. La présence de charbons dans les couches 2015 et 2002 indique peut-être une zone de rejet pour une activité impliquant la combustion.

La structure de combustion 2031 (fig. 13) est polylobée (longueur maximale : 2,5 m). Deux espaces peuvent y être distingués. La partie à l'ouest est profonde et vaste (largeur : 1,8 m, profondeur : $60 \mathrm{~cm}$ ). La zone orientale est plus étroite, 1,3 m de largeur, et son fond, situé $20 \mathrm{~cm}$ plus haut, est tapissé de charbons de bois. La limite formée par cette couche est parfaitement nette trahissant un effet de paroi. Aucune trace de rubéfaction n'a été mise en évidence.

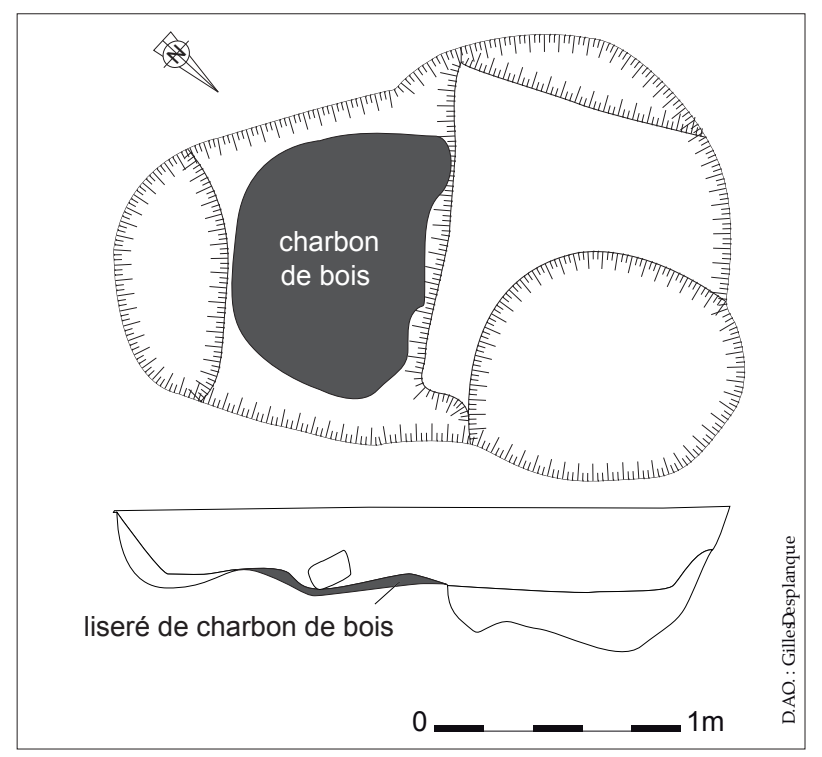

Fig. 13 - La structure 2031.
Enfin, deux trous de poteau isolés (structures 2007 et 2013) et une fosse de rejet contenant des charbons de bois, des fragments de terre cuite architecturale et de torchis (St 2014) ont été découverts.

\section{LE MOBILIER ARCHÉOLOGIQUE}

\section{Le mobilier métallique et le mobilier d'origine animale}

Le comblement des fonds de cabane a livré un mobilier non céramique classique pour la période, mais quelques éléments méritent un intérêt plus soutenu. Issu de la structure 2014, un accessoire en fer doté d'un crochet de suspension sur une extrémité et d'une paire de " cornes » recourbées sur l'autre peut être interprété comme un élément de suspension de crémaillère (fig. 14-10). Signalons deux petites aiguilles en alliage cuivreux mises au jour dans les structures 2001 et 2006 (fig. 14-1 et 14-3). Elles présentent, sous leur chas, sur un à deux centimètres, un décor d'incisions en zigzag permettant une meilleure préhension. Un élément (fig. 14-2) pourrait s'apparenter aux poinçons de type IIB (GORET 1997, p. 108), mais ses faibles dimensions plaident plutôt pour une aiguille, destinées à des activités grossières. Deux paires de forces (fig. 14-6 et 7), des lames de couteaux, ainsi qu'une série de pesons en terre cuite et en craie sont aussi attestées.

À côté de l'outillage, on relève la présence, dans le fond de cabane 2012, d'un fermoir d'aumônière en fer (fig. 14-8), remarquable par sa morphologie générale et dont les extrémités recourbées forment deux têtes zoomorphes stylisées se faisant face (rapaces, chevaux ?). Daté en MA1-MA2 (470/480$560 / 570$ ) en contexte funéraire (Legoux et al. 2006), sa présence dans l'habitat apporte quelques données chronologiques supplémentaires sur la pérennité de ce type d'objet au cours des phases postérieures. La même structure a livré une pince à épiler en alliage cuivreux à larges mors débordants (fig. 14-5), relativement rare dans ce type de contexte. Peut-on imaginer qu'une bourse et son contenu aient été rejetés dans ce fond de cabane abandonné ? Toujours est-il que ce petit mobilier (fermoir et pince à épiler), assez exceptionnel en contexte d'habitat, est plus fréquemment attesté en contexte funéraire, en particulier dans des tombes masculines de haut rang comme à Cutry dans la Meurthe-et-Moselle (LegOux 2005). Mentionnons un fragment de peigne en os ou bois de cerf caractérisé par une large plaque relativement fine dont les longueurs sont façonnées de dents, consolidée par deux baguettes transversales rivetées, décorées de quatre incisions parallèles (fig. 14-12). Ce type de peigne est très fréquent au cours des $\mathrm{VI}^{\mathrm{e}}$ et $\mathrm{VII}^{\mathrm{e}} \mathrm{s}$. et rien ne permet de fournir une chronologie plus fine (Petitjean 1995). Deux perles ont aussi été mises au jour dans le comblement des bâtiments excavés 


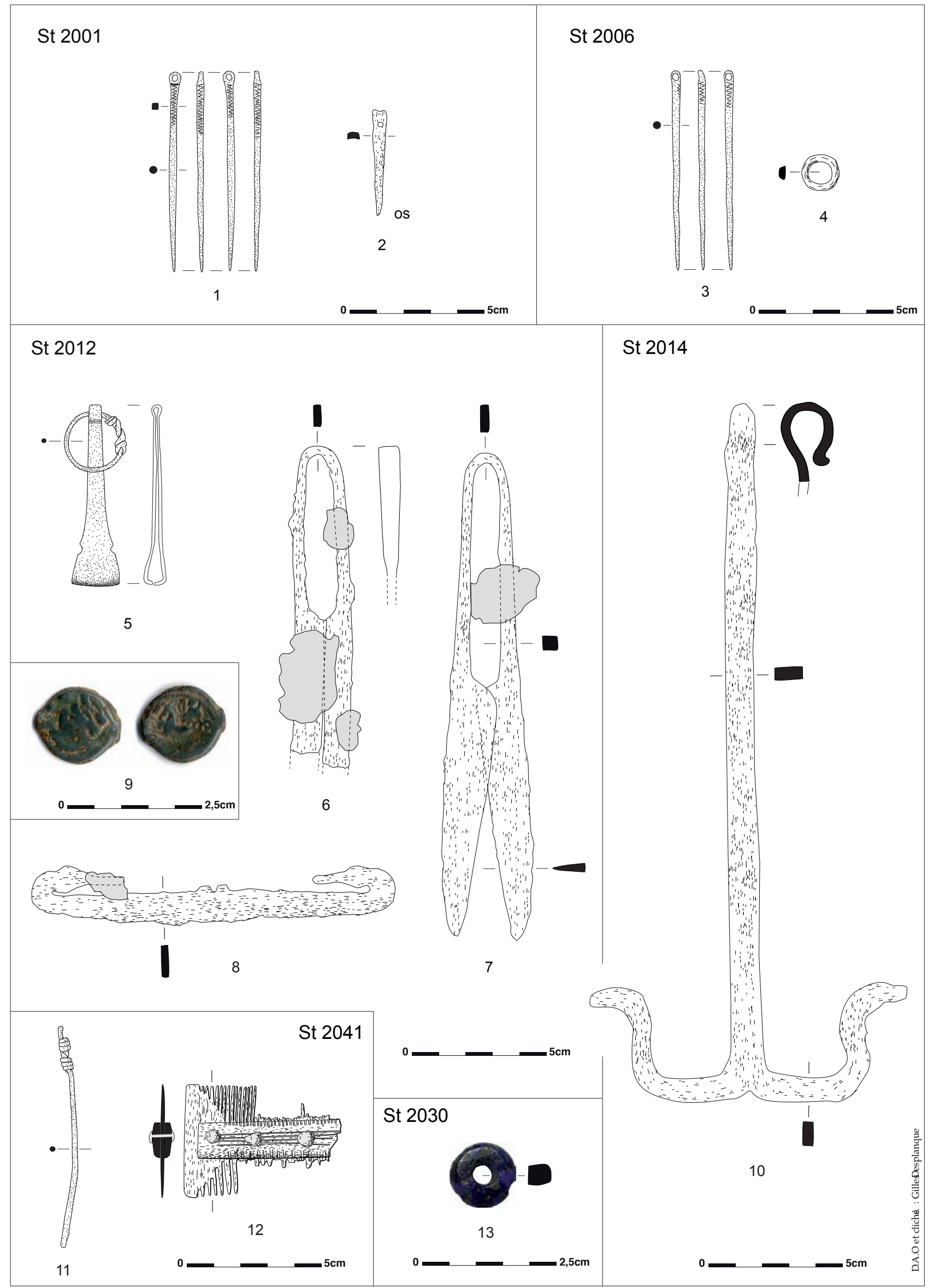

Fig. 14 - Les objets mérovingiens. 
(fig. 14-4 et 13). Il s'agit d'une perle translucide bleutée dans la structure 2030 et d'un exemplaire de section assez fine et dans un matériau indéterminé (ambre très corrodé ?) dans la structure 2006.

Signalons enfin la présence dans la structure 2012 d'une monnaie gauloise, identifiée par Benoît Filipiak (Université de Bourgogne, UMR 5605) comme une monnaie issue de la cité des Rèmes (fig. 14-9). Trois portraits accolés sont figurés sur le droit, alors que sur le revers est représenté un bige allant vers la gauche. Frappé entre 60 et 25 avant J.-C., ce type circule encore sous Auguste. Sa présence en contexte mérovingien est probablement à mettre sur le compte des nombreuses récupérations d'objets issus de périodes antérieures et investis d'une valeur symbolique (amulette?). Les monnaies gauloises ou romaines, fragments de hache néolithique... figurent en effet en bonne place dans les sacoches mises au jour dans les tombes des $\mathrm{VI}^{\mathrm{e}}$ et $\mathrm{VII}^{\mathrm{e}}$ siècles.

\section{Le mobilier en verre}

Une série de fragments de verrerie vient compléter le mobilier non céramique (fig. 15). On note la présence, dans la structure 2041, d'un bord de coupe de type 81 , à ouverture dite rebrûlée et caractérisé par un cordon d'émail (FEYEuX 2003, p. 165). Deux exemplaires très proches sont conservés au Musée de Laon (inv. 0.1001 et 0.997), ainsi qu'un exemplaire mis au jour à Chalandry dans l'Aisne (FEYEUX 2003, p. 171). Dans cette même structure, on y relève aussi le fragment d'un gobelet ou d'un cornet dont la lèvre serait très peu marquée, caractérisé par un cordon émaillé sous la lèvre (FEYEUX 2003, p. 82

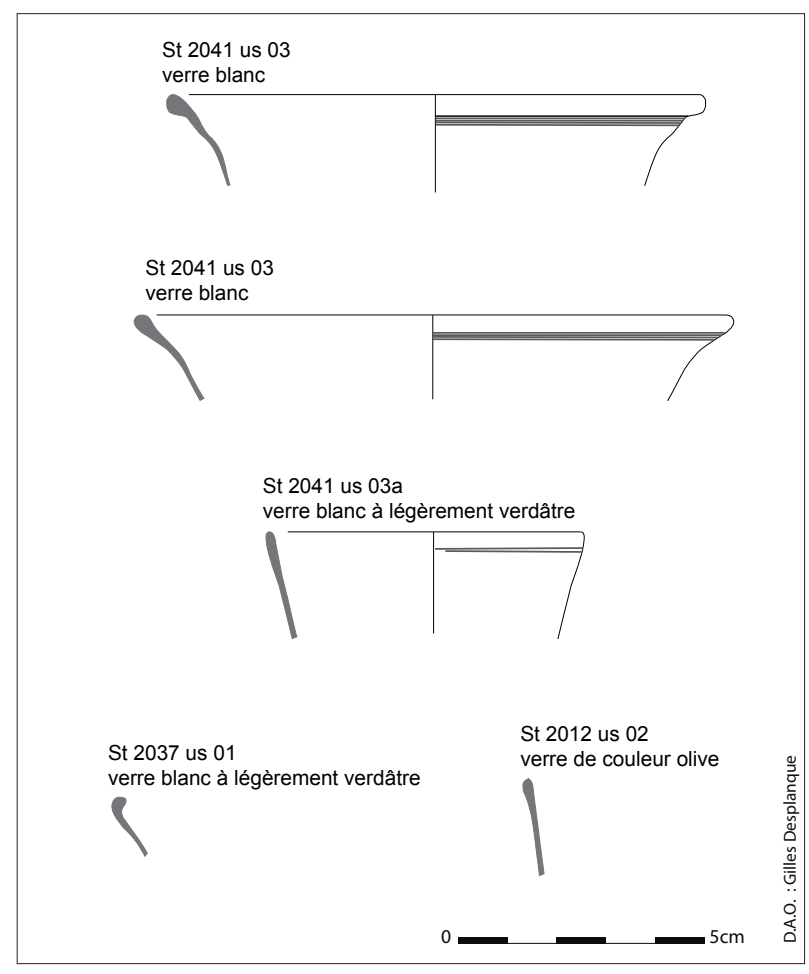

Fig. 15 - Les objets en verre mérovingien. et 90, type 51.1 ou 52.1 ?). Même peu nombreuses, les formes restituables semblent s'intégrer dans l'ensemble des occurrences en verre attestées dans la région. Les cartes de répartition témoignent en effet de concentrations importantes des types dont participent les exemplaires étudiables de Fresnoyle-Grand, au point que, depuis le sud de la Marne jusqu'au nord des Ardennes, en englobant le département de l'Aisne, les témoignages d'activités verrières semblent ne pas faire de doutes (FEYEUX 2003, p. 220-221).

\section{Le mobilier céramique (A. CORSIEZ)}

Vingt trois structures, dominées par les fonds de cabane ont livré 1563 tessons réduits à 188 individus. Quatre catégories ont été reconnues, toutes très proches. Cette céramique, à l'instar de celle d'époque gallo-romaine, est fragmentée et les surfaces sont souvent abîmées et usées, ce qui rend difficile l'attribution à la céramique rugueuse sombre ou la céramique polie. La méthodologie employée est la même que pour l'époque antique.

\section{Catégories et groupes de pâte}

La céramique rugueuse sombre (CRB) : il s'agit d'une catégorie similaire dans sa fonction et ses techniques à la céramique rugueuse sombre (RUB) de l'Antiquité. Elle est cuite en mode réducteur et dominée par les teintes noires. Elle est tournée, mais les parois sont épaisses et la panse vers le fond est parfois affinée après tournage par enlèvement de matière, ce qui donne un effet de facettage. Le fond est simple, non retravaillé et très régulièrement, on observe les traces du décollage à la ficelle. Les surfaces sont rugueuses. Il s'agit de céramique culinaire, reconnaissable notamment par les caramels alimentaires, parfois épais, que l'on retrouve quasi systématiquement à l'intérieur et l'extérieur des pots et écuelles. On peut également observer régulièrement une fine pellicule calcaire à l'intérieur des pots, induite par des cuissons à l'eau. On connaît dans l'Aisne trois grandes aires de fabrication reconnaissables aux pâtes : le Laonnois, le Tardenois et le Soissonnais (BAYARD \& THOUVENOT 1993). L'étude des pâtes à la loupe binoculaire a permis d'affiner les hypothèses de provenance d'une partie des céramiques.

Groupe de pâte $A$ : pâtes contenant du quartz transparent à blanc, émoussé, de fin à petit calibre abondant. Quelques pâtes ont des grains de quartz de gros à très gros calibre, blancs, transparents ou jaunes, peu à moyennement abondants. La matrice est majoritairement brillante, légèrement feuilletée ou non. Il s'agit d'un groupe de pâte similaire aux pâtes arrageoises antiques.

Groupe de pâte B : matrice luisante, contient du quartz fin de petit calibre, blanc, transparent, 
émoussé, abondant ; de fines à petites inclusions noires moyennement abondantes à abondantes ; de fines à petites inclusions blanches peu abondantes; de fins à petits oxydes de fer rouge, peu à moyennement abondants ; parfois des tessons ont des inclusions de quartz de moyen calibre, blanc, transparent, émoussé, moyennement abondant et de fines à petites inclusions noires moyennement abondantes avec une matrice bien visible. Ce groupe de pâte est très proche du groupe de pâte gallo-romain RUB D que l'on observe dans le nord de la cité des Viromanduens à partir du Bas-Empire (CoRSIEZ 2008, p. 168 ; Dubois \& Bourson 2001, p. 193).

Groupe de pâte C : pâtes à gros grains de quartz blancs peu abondants, et de fin à petit calibre blancs et transparents abondants, inclusions de calcaire de petit à gros calibre moyennement abondantes à abondantes. Il s'agit du groupe de pâte des ateliers du Soissonnais.

Groupe de pâte $D$ : pâtes à quartz de fin à petit calibre blancs émoussés et transparents à arêtes vives moyennement abondants, les quartz transparents sont inclus dans la matrice, peu visibles; oxydes de fer rouge de fin à petit calibre moyennement abondants, rares oxydes de gros calibre ; dans certains fragments, les inclusions rouges sont peu abondantes.

Bien que la céramique ait été datée des $\mathrm{VI}^{\mathrm{e}}-\mathrm{VII}{ }^{\mathrm{e}} \mathrm{s}$., l'étude des pâtes a montré que la majorité d'entre elle présente des caractéristiques appartenant à des groupes de pâtes antiques, notamment les groupes de pâtes A et B. Il est ainsi possible d'envisager une continuité de l'activité potière sur les lieux même des grands ateliers gallo-romains régionaux. En revanche, le groupe $C$, probablement issu des ateliers du Soissonnais se démarque des productions galloromaines de Soissons à dégraissant nummulitique. Il s'agit d'un autre banc d'argile à calcaire, plus fin (THOUVENoт 1998). Une autre partie des pâtes peut provenir du Laonnois mais l'absence d'échantillons de comparaison n'a pas permis de les identifier. D'une manière générale, ces pâtes ne sont plus aussi fines que celles auxquelles elles succèdent, de même que les techniques de fabrication ont perdu de leur qualité. Le graphique de la figure 16 montre les proportions des groupes de pâtes au sein de la céramique commune rugueuse sombre.

La céramique polie (CP) : il s'agit de la deuxième catégorie caractéristique de l'époque mérovingienne. Elle est surtout représentée par les vases biconiques. Les surfaces sont polies au galet de façon irrégulière, ce qui donne un aspect facetté aux surfaces. Aux périodes précoces, le polissage est plus régulier et s'apparente au lissage. Sur le site, elle est systématiquement décorée à la molette ou au poinçon. Les parois restent épaisses, la cuisson réductrice. On peut attribuer cette catégorie au

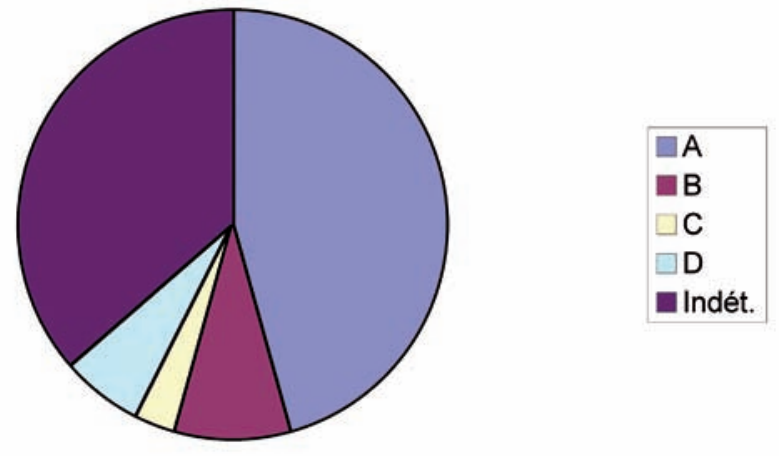

Fig. 16 - Proportions des groupes de pâtes au sein de la commune rugueuse sombre (CRB).

service de table, bien que parfois des caramels de cuisson indiquent qu'elle ait pu servir pour cuire des aliments. Les pâtes sont les mêmes que celles de la CRB mais il a pu être observé des variantes des pâtes $\mathrm{A}$ et $\mathrm{B}$, plus fines.

La céramique rugueuse cuite en mode oxydant (CRA) : cette appellation couvre les céramiques à surface claire, sans qu'il n'ait été possible de distinguer une cuisson volontairement oxydante ou une réoxydation partielle accidentelle.

La céramique modelée (CM) : céramiques montées à la main, aux parois et bords irréguliers. Les pâtes assez grossières, peuvent contenir du dégraissant à base de fibres végétales. L'intérieur est souvent recouvert de caramel alimentaire.

La céramique résiduelle: dans les assemblages mérovingiens, il est fréquent de retrouver des intrusions de céramique d'époque gallo-romaine. Certaines sont des céramiques encore fabriquées au $\mathrm{V}^{\mathrm{e}} \mathrm{s}$., période de transition encore peu connue pour l'habitat (H I de l'Aisne, BAYARD \& THOUVEnOT 1993) et d'autres sont issues des structures galloromaines recoupées lors de l'installation de l'habitat mérovingien. Elle devient résiduelle à partir de l'horizon II de l'Aisne. La céramique résiduelle est grisée dans le tableau II qui donne le récapitulatif des quantités de céramique par catégorie (fig. 17)

\section{La typologie et la chronologie}

La typologie est commune à la céramique rugueuse et à la céramique polie, car certains types sont réalisés dans l'une ou l'autre catégorie.

Pot P1 : il s'agit du type le plus abondant, un pot à panse globulaire à court col concave non délimité et lèvre oblique. La lèvre présente deux variantes : lèvre repliée avec une gouttière large ou petite (P1a) et lèvre simple non repliée avec une gouttière peu marquée (P1b). Ce pot traverse les horizons II et III de l'époque mérovingienne de l'Aisne sans changement morphologique, mis à part la variante 


\begin{tabular}{|l|c|c|c|}
\hline Catégorie & NR & $\%$ NR & NMI \\
\hline CP & 182 & 11,7 & 26 \\
\hline CRB & 1062 & 68 & 116 \\
\hline CM & 36 & 2,3 & 5 \\
\hline CRA & 11 & 0,7 & 0 \\
\hline TS & 5 & 0,3 & 2 \\
\hline ITS & 3 & 0,2 & 1 \\
\hline TN & 2 & 0,1 & 1 \\
\hline FRB & 5 & 0,3 & 1 \\
\hline VRP & 3 & 0,2 & 3 \\
\hline RUB & 91 & 5,8 & 19 \\
\hline CC & 79 & 5,1 & 2 \\
\hline MD & 4 & 0,3 & 1 \\
\hline MO & 2 & 0,1 & 2 \\
\hline DO & 22 & 1,4 & 3 \\
\hline AM & 1 & 0,1 & 0 \\
\hline INDET. & 53 & 3,3 & 6 \\
\hline
\end{tabular}

Écuelle EC 3 : écuelle à lèvre en pointe sur l'extérieur et petite collerette médiane. Il s'agit du type A3b de la vallée de l'Aisne, présent dans la deuxième moitié $d u V^{e} \mathrm{~s}$. On note la présence de caramel alimentaire interne sur un exemplaire en céramique polie et sur un autre en céramique rugueuse. On la retrouve à Goudelancourt-lèsPierrepont, à Savy (HaRnaY \& THOUvenot 2001, pl. 28) mais aussi à Soissons (BAYARD 1994, THOUvENOT 1998, figure 4).

Écuelle EC 4 : type peu fréquent à profil en $\mathrm{S}$ ramassé, le col est très court et la lèvre petite.

Écuelle EC 5 : type peu fréquent, écuelle à parois simple et bord arrondi. On note la présence de caramel alimentaire interne. Exemplaires du même type à Monchy-Lagache et Savy (HARNAY \& THOUvenOt 2001, pl. 28), datés de l'horizon III.

Écuelle EC 6 : écuelle en céramique polie, proche du type EC 4, mais avec la panse rainurée.

Tab. II - Proportions des groupes de pâtes au sein de la commune rugueuse sombre (CRB).

P2, qui semble plus tardive dans l'horizon III et l'apparition du fond lenticulaire à la fin du VII ${ }^{e} s$. (BAYARD \& THOUVENOT 1993). On note la présence systématique de caramel alimentaire, souvent en couche épaisse et accompagné d'une fine pellicule calcaire, déposée lors de cuisson à l'eau.

Pot $P 2$ : pot du même type que le précédent mais lèvre soulignée d'une simple rainure. On note la présence de caramel alimentaire.

Pot P3 : pot à bord arrondi et col concave. Il semblerait que ce soit une variante rare du P1 (BAYARD \& THOUVENOT 1993, H III).

Mortier MO1 : mortier à petite collerette soulignant la lèvre, râpe interne. Type caractéristique de l'horizon III de la vallée de l'Aisne. On le trouve sur le site proche de Athies (Harnay \& THOUvenot 2001, pl. 28).

Écuelle EC 1 : écuelle carénée dont la forme est proche de l'écuelle Alzei 9/11 en sigillée. Le vase n'est présent qu'à un exemplaire confirmé sur le site. Il s'agit du type A1 de la vallée de l'Aisne, horizon III (BAYARD \& THOUVENOT 1993), elle est présente à Goudelancourt-lès-Pierrepont (BAYARD 1994, fig. 4) et à Monchy-Lagache (HARNAY \& THOUvENOT 2001, pl. 28). On note la présence de caramel alimentaire. Elle est classée dans la céramique polie.

Écuelle EC 2 : écuelle carénée à col concave et ressaut, que l'on retrouve en céramique polie ou en céramique rugueuse. On la trouve à Soissons (Thouvenot 1998, fig. 43.5) et à Goudelancourt-lèsPierrepont (BAYARD 1994, fig. 4) dans des ensembles de l'horizon III de la vallée de l'Aisne.

Écuelle EC 7 : écuelle en céramique polie, à lèvre rentrante soulignée d'une rainure.

Vase biconique VB1 : court col concave souligné d'une baguette et carène médiane. Il s'agit du vase biconique le plus caractéristique de l'époque mérovingienne. Il correspond au type $C 5$ de la vallée de l'Aisne, fréquent au $\mathrm{VI}^{\mathrm{e}}$ s. et au type A de Legoux, Perin et Vallet (Legoux, Périn \& VAlLet 2006), daté du Mérovingien ancien 1 à 2 (fin $V^{e}$ jusque $3^{\mathrm{e}}$ quart $\mathrm{du} \mathrm{VI}^{\mathrm{e}} \mathrm{s}$.). On le trouve à Savy, daté de l'horizon III de la vallée de l'Aisne (HARnAY \& THOUVEnOt 2001, pl. 28).

Vase biconique VB2 : bord arrondi, col concave peu marqué, souligné d'une arête. Il correspond au type D5 de la vallée de l'Aisne daté du dernier tiers du VI ${ }^{\mathrm{e}}$ au début du $\mathrm{VII}^{\mathrm{e}} \mathrm{s}$.

Vase biconique VB 3 : lèvre simple oblique, le haut de la panse est décoré de trois rainures. Présent à un seul exemplaire, il correspond au type B8b de la vallée de l'Aisne qui apparaît au début du $\mathrm{VIII}^{\mathrm{e}} \mathrm{s}$. Il est caractéristique du Nord de la France et de la Belgique (BAYARD \& THOUvenot 1993, p. 313).

Vase biconique VB 4 : vase biconique à panse supérieureondulée. Ils'agit d'un typecaractéristique de $1^{\prime}$ Aisne et de la $2^{\mathrm{e}}$ moitié du VII ${ }^{\mathrm{e}} \mathrm{s}$. (BAYARD \& Thouvenot 1993, p. 302, MR 1 à 3 de Legoux, Périn \& VALLET 2006).

Cruche CR1 : cruche dont le profil de la lèvre est le même que celui du P1. L'anse est attachée sur la lèvre. Les deux fragments de CR1 présents sur le site ne sont conservés qu'au niveau de la lèvre. Une molette de double ligne de carrés, imprimée deux fois, décore le haut de la panse. 


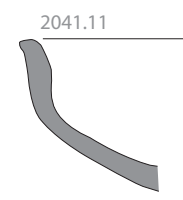

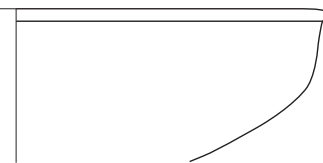

Ec 1

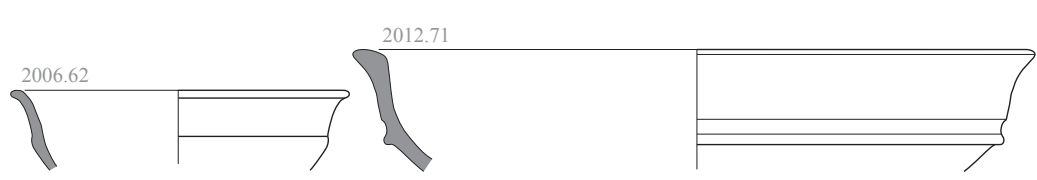

Ec2

Ec3

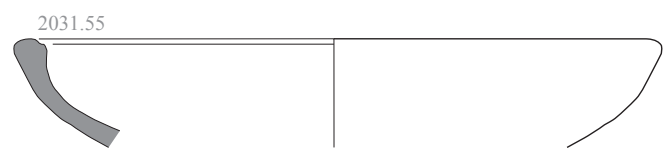

Ec5

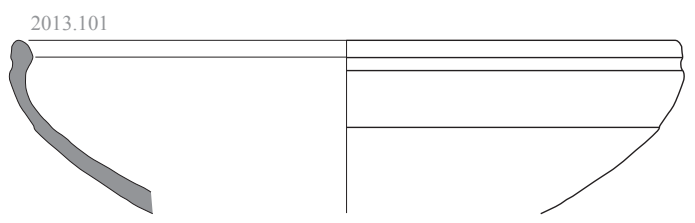

Ec7
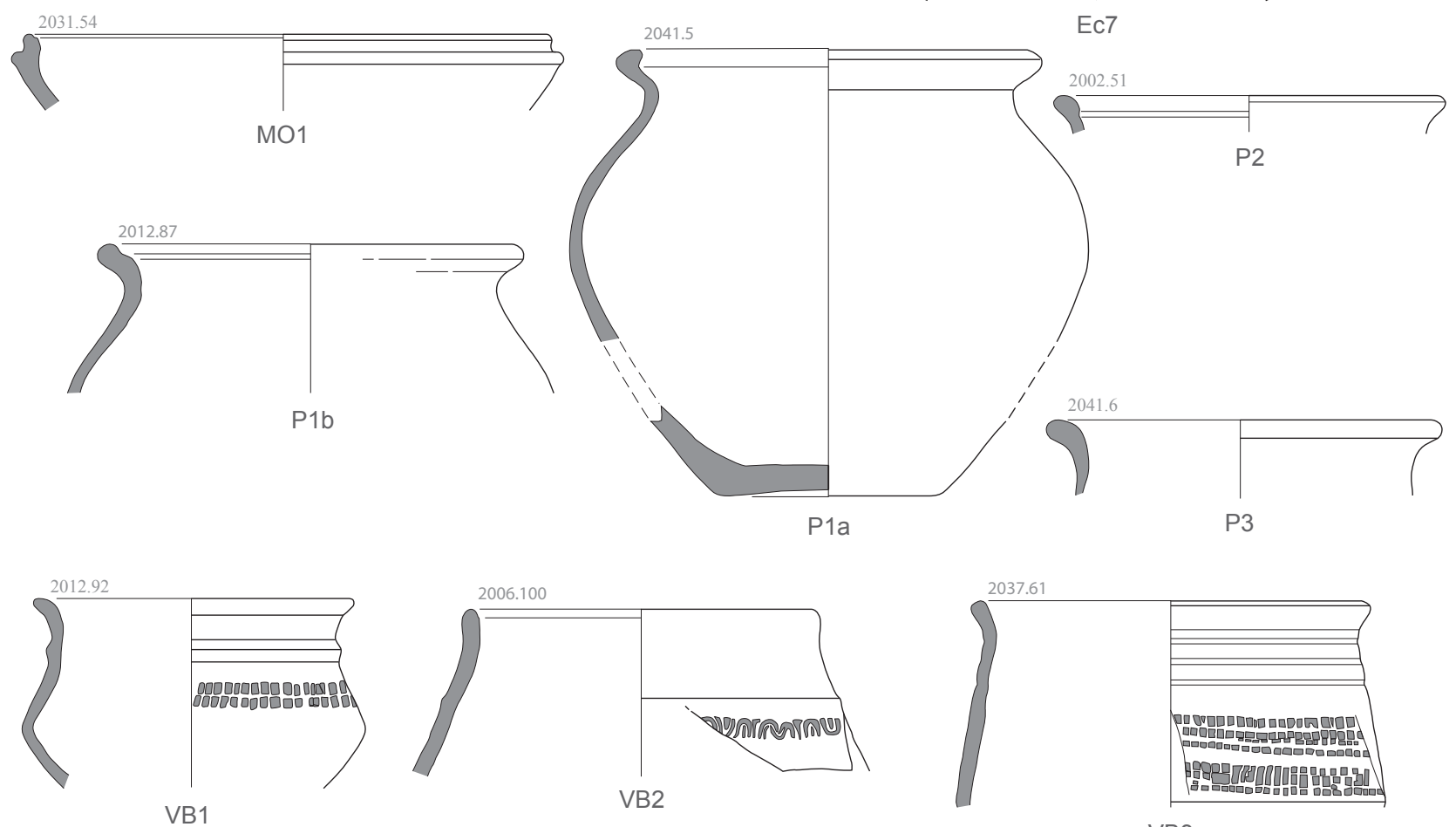

VB3
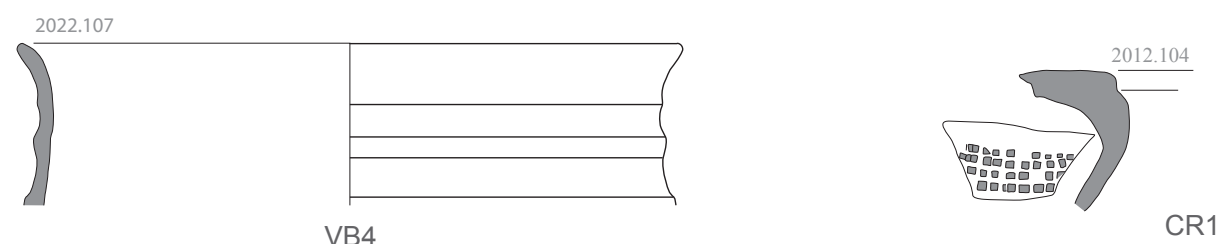

Fig. 17 - Planche typologique sur la céramique rugueuse sombre (CRB) mérovingienne et les vases biconiques (CP). Éch. 1/3, dessin et DAO A. CORSIEZ.

\section{Les molettes}

Les molettes (fig. 18) sont caractéristiques de la céramique polie. Cette céramique, abondante en contexte funéraire, a permis une sériation qui a fourni des fourchettes chronologiques pour les molettes. Dix types de molettes bien connues et un poinçon ont pu être identifiés. Les molettes sont souvent illisibles car les potiers ont pu repasser leur outil par dessus ou les polir partiellement. La chronologie des décors sera discutée pour chaque structure.

Le graphique(fig.19)montreun facièstypologique caractéristique d'un habitat. Les pots à cuire P1 à P3 sont en supériorité massive et les autres types, 


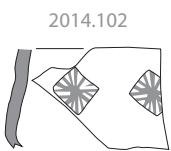

Poinçon

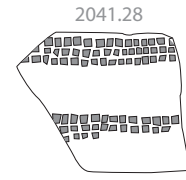

Décor $\mathrm{N}^{\circ} 2$

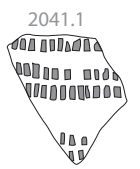

Viag

.

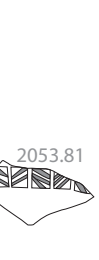

Décor $n^{\circ} 13$

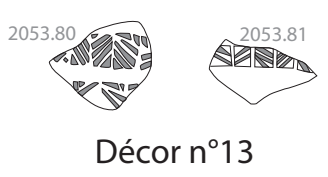

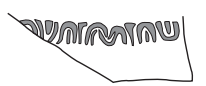

Décor $n^{\circ} 17$
2006.109
WWWIDID

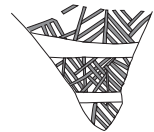

Décor $n^{\circ} 13$

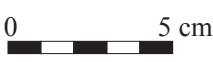

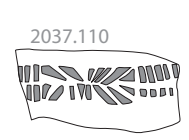

Décor $\mathrm{n}^{\circ} 12$
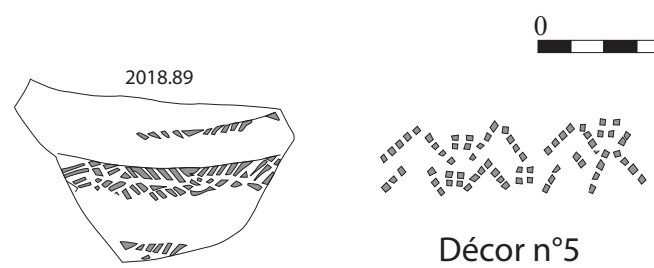

Fig. 18 - Planche récapitulative des décors de molette du site ; les $n^{\circ}$ suivent le classement de S. Thouvenot dans l'article Bayard \& Thouvenot 1993, (éch. 1/3, dessin et DAO A. Corsiez).

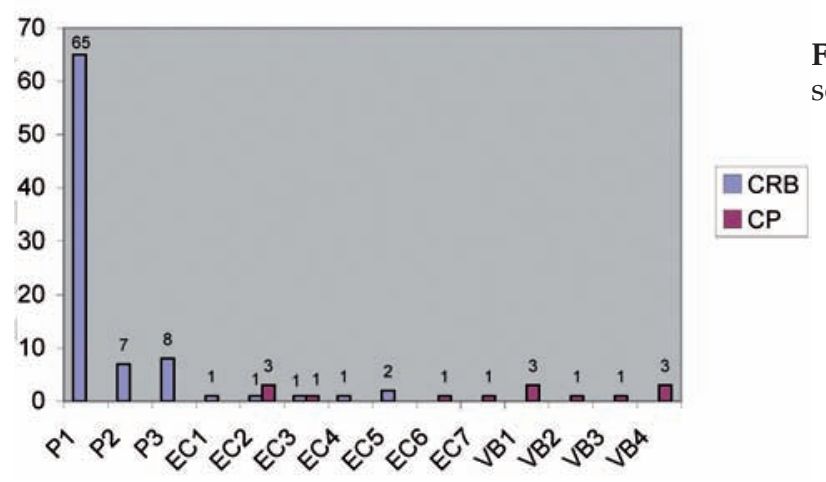

Fig. 19 - Répartition des types au sein de la céramique commune sombre et de la céramique polie.

Fig. 20 - Céramique de la structure 2012 (éch. 1/3, dessin et DAO A. CORSIEZ).
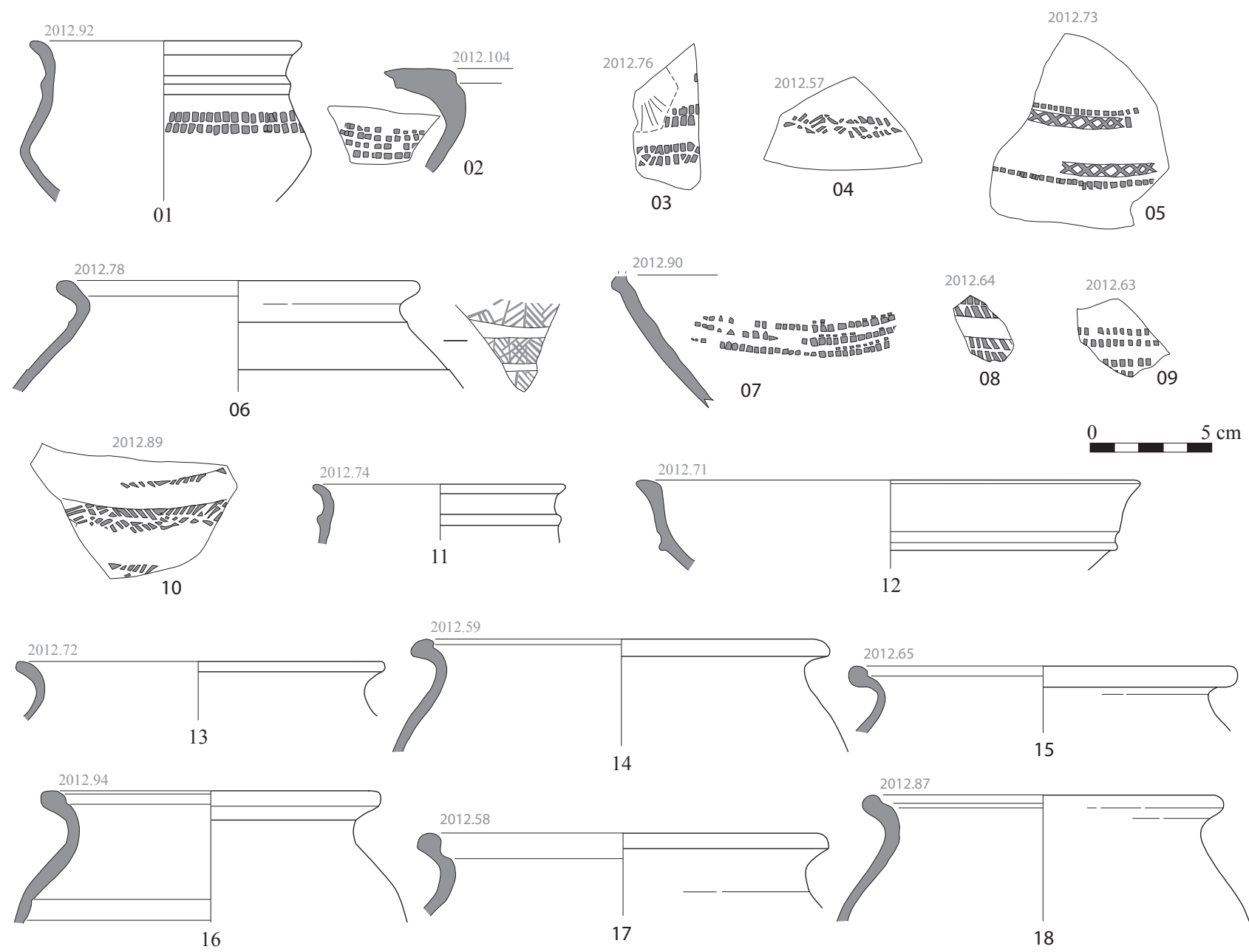

14

15 
écuelles et vases biconiques, complètent la vaisselle pour la consommation de la nourriture mais aussi pour la cuisson, comme l'écuelle 1 en CRB. Les vases biconiques sont peu abondants, au contraire des nécropoles où ils sont majoritaires.

\section{CHRONOLOGIE}

\section{Les fonds de cabane datés}

2012 (fig. 20) : 421 tessons dont 50 individus. Il s'agit du lot céramique le plus important du
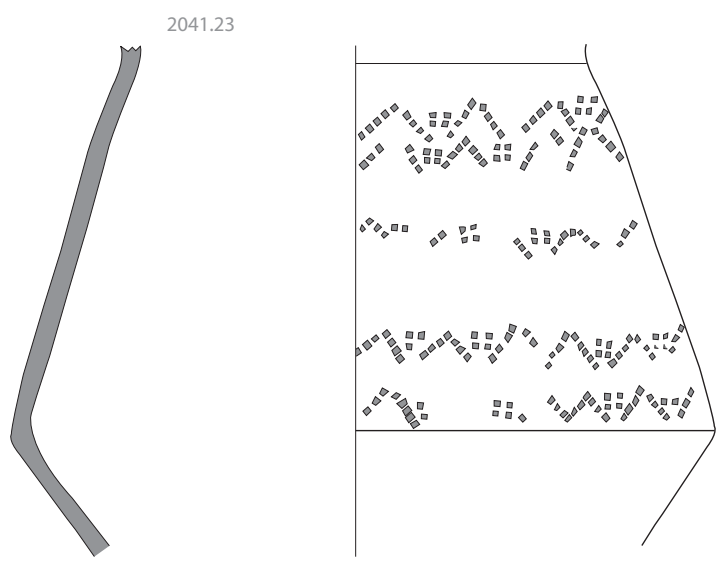

2041.1

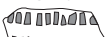

Perang nond

(20

(bi: 20

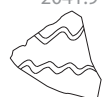

21

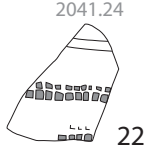

19

2041.28

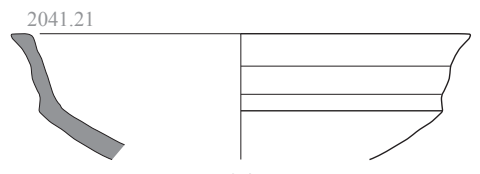

24

23

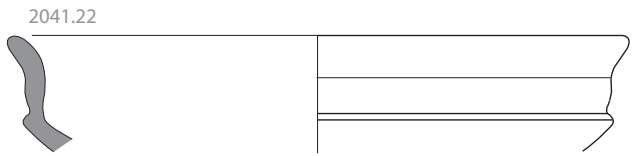

25
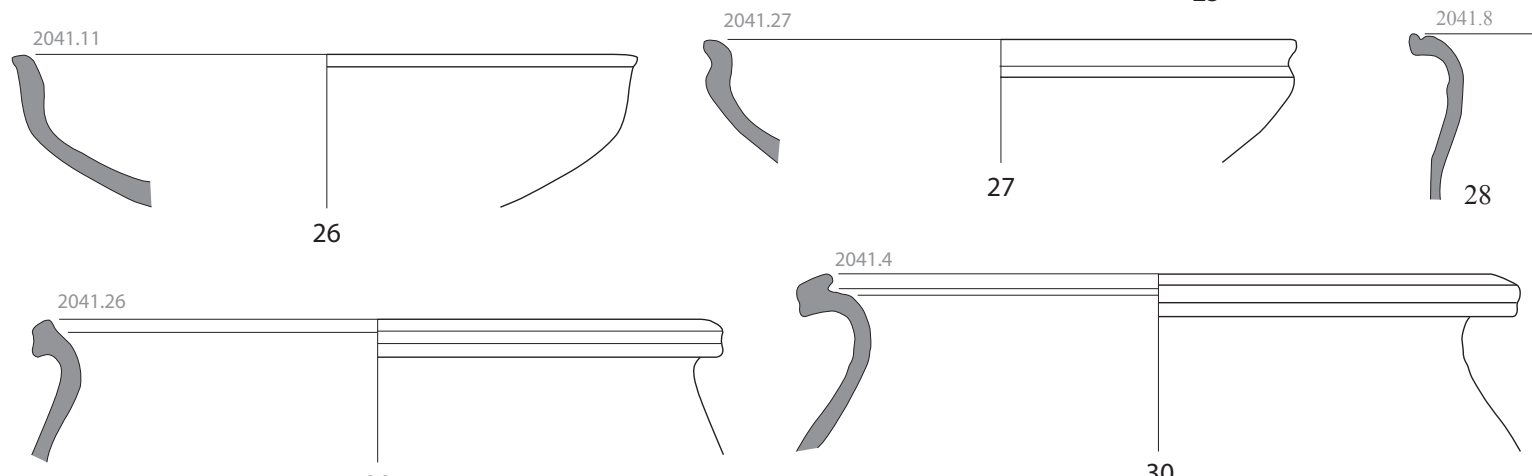

29

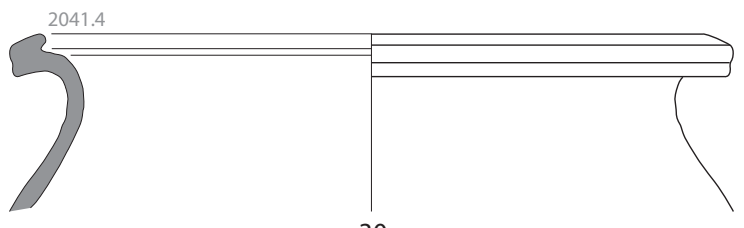

30
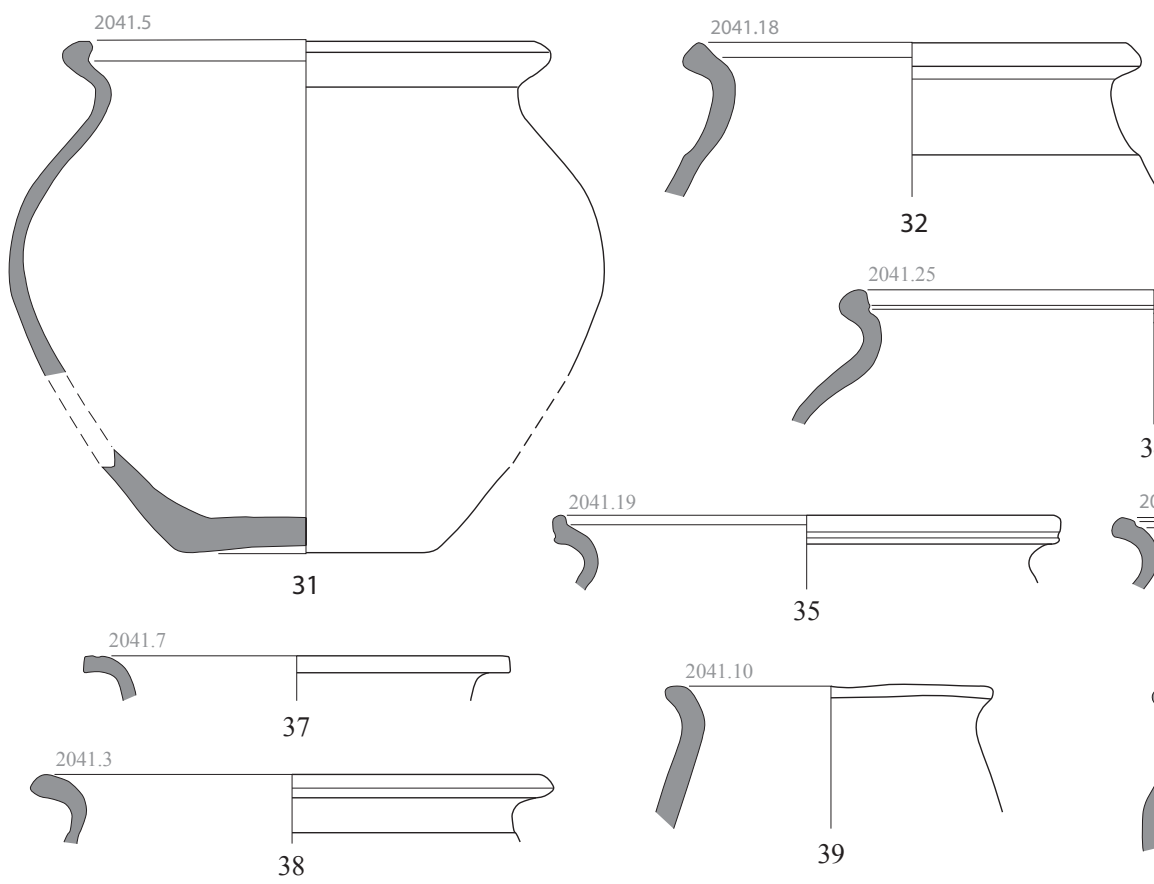

32
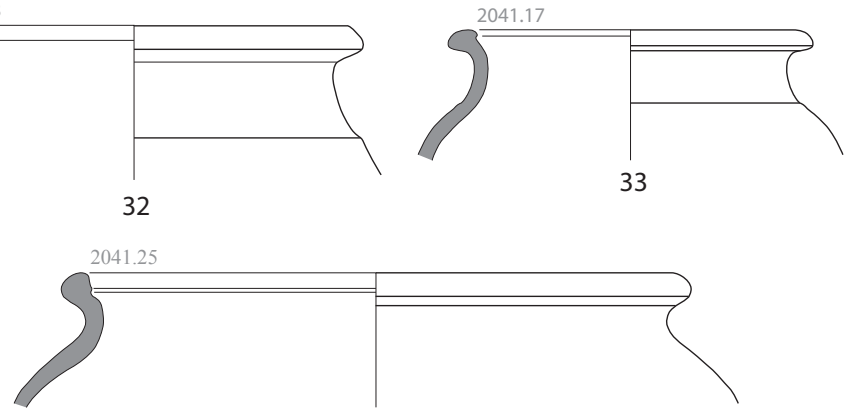

34
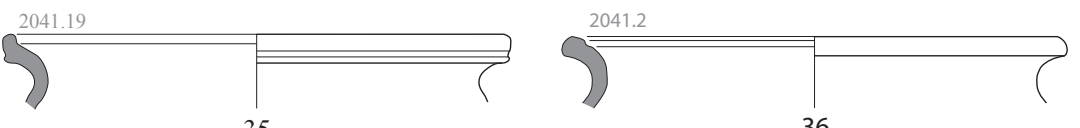

35

36

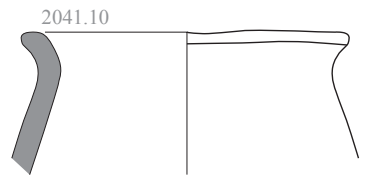

39

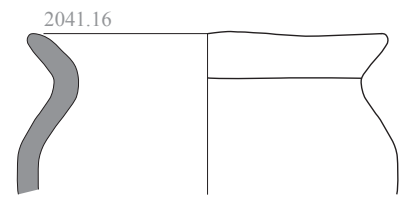

40

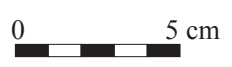

Fig. 21 - Céramique de la structure 2041, (éch. 1/3, dessin et DAO A. CoRSIEZ, sauf nº 19, 21, 23, 26 et 31, dessins Pôle archéologique - CG 02). 
site. On note la présence du vase biconique VB1, précédemment daté du $\mathrm{VI}^{\mathrm{e}} \mathrm{s}$. ainsi que sa molette. Cette même molette se retrouve sur deux autres vases. Le vase $n^{\circ} 5$ est décoré d'une molette décor $\mathrm{n}^{\circ} 13$ (BAYARD \& THOUVENot 1993), datée du $2^{\mathrm{e}}$ tiers $\mathrm{du} \mathrm{VI}^{\mathrm{e}} \mathrm{s}$. à la fin de ce même siècle. Le faciès est typique de l'horizon III de la vallée de l'Aisne et peut ainsi être daté $\mathrm{du}$ milieu $\mathrm{du} \mathrm{VI}^{\mathrm{e}} \mathrm{s}$. à la première moitié du VII ${ }^{\mathrm{e}} \mathrm{s}$.

2041 (fig. 21) : 333 tessons et 39 individus. C'est après la structure 2012, le fond de cabane qui a livré le lot le plus important de céramique. Un fragment de panse de pichet du type H1 (fig. 21, n 19), défini par Sylvain Thouvenot (BAYARD \& THOUVENOT 1993), est présent dans cette structure avec le même décor que celui représenté dans l'article précédemment cité, une molette de type $n^{\circ} 5$, datée de la fin du $\mathrm{V}^{\mathrm{e}} \mathrm{s}$. au milieu du $\mathrm{VI}^{\mathrm{e}} \mathrm{s}$. Plusieurs tessons avec un décor ondé sont datables de la $2^{\mathrm{e}}$ moitié du $\mathrm{VI}^{\mathrm{e}} \mathrm{s}$. Les écuelles 2 et 3 sont aussi datables de la $2^{\mathrm{e}}$ moitié $\mathrm{du} \mathrm{VI}^{\mathrm{e}} \mathrm{s}$. L'ensemble de la céramique correspond au faciès de l'horizon III de la vallée de l'Aisne.

2006 (fig. 22) : 215 tessons et 24 individus. Le type VB2 est connu dans le dernier tiers du VI $\mathrm{s}$. jusqu'au début du VII ${ }^{\mathrm{e}} \mathrm{s}$. ainsi que son décor d'oves (décor $n^{\circ} 17$ défini par Sylvain Thouvenot). L'écuelle carénée 3 est typique de l'horizon III de l'Aisne. Cette structure appartient à cet horizon mais peut néanmoins voir sa fourchette chronologique être raccourcie de la fin $\mathrm{du} \mathrm{VI}^{\mathrm{e}} \mathrm{s}$. à la première moitié du VII $\mathrm{e}$.

$2001: 59$ tessons et 5 individus. Deux types ont pu être identifiés : un pot P1 et un vase biconique VB4 qui est daté de la $2^{\mathrm{e}}$ moitié du VII ${ }^{\mathrm{e}} \mathrm{s}$., une période de transition encore mal connue entre l'horizon classique III et l'horizon IV marquant la fin de l'époque mérovingienne. Aucun élément ne nous permet de placer cette structure à l'horizon IV.

2022 (fig. 22) : 84 tessonset 12 individus. Aucun P1 n'est présent mais en revanche on trouve sa variante tardive à lèvre rainurée (P2). On trouve aussi un pot à lèvre éversée et col concave (variante de P3 ?), lui-même tardif. Un vase biconique 4 complète cet assemblage et un fond lenticulaire nous confirme une datation fin VII ${ }^{\mathrm{e}}$-VIII ${ }^{\mathrm{e}}$ s., soit l'horizon IV de la vallée de l'Aisne. Un tesson très original a attiré notre attention : un fond décoré d'une molette sur sa surface intérieure. Aucune autre occurrence n'a été retrouvée dans les différents articles compulsés.

2025 : 30 tessons et 5 individus. Aucun élément probant ne permet de donner une datation précise. On peut néanmoins émettre l'hypothèse que cette structure appartient au moins à l'horizon III sinon à la période de transition avec l'horizon IV comme pourrait le suggérer la présence d'une panse de
2028 : 23 tessons et 2 individus : seul un vase à lèvre rainuré P2 a été identifié. Il permet de proposer une datation de la fin du VI jusqu'au début du VII ${ }^{\mathrm{e}} \mathrm{s}$.

2037 (fig. 22) : 34 tessons et 6 individus. La présence du vase biconique 4 (D8b de la vallée de $\mathrm{l}^{\prime}$ Aisne) indique une datation à partir du début du VII ${ }^{e}$ s. Le décor $n^{\circ} 12\left(n^{\circ} 52\right)$ est daté de la deuxième moitié du VI ${ }^{\mathrm{e}} \mathrm{s}$. jusqu'au début du VII ${ }^{\mathrm{e}} \mathrm{s}$. On peut dater ce fond de cabane de la première moitié du VII ${ }^{\mathrm{e}}$ s., à la fin de l'horizon III de la vallée de l'Aisne.

\section{Les autres structures datées}

2002 : 103 tessons et 20 individus. Il s'agit d'une couche d'épandage recouvrant des structures d'époque gallo-romaine. La majorité du mobilier est gallo-romain, provenant des structures du dessous. Néanmoins la présence de P1 et P2 en CRB indique une datation à l'horizon III.

2014 (fig. 22) : 45 tessons et 7 individus. Cette structure, grâce au vase biconique à poinçon, peut être datée $\mathrm{du} \mathrm{VI}^{\mathrm{e}} \mathrm{s}$. sans que les autres formes ne puissent apporter de précisions. Néanmoins, l'homogénéité de datation des autres structures à l'horizon III incite à penser que cette structure pourrait être datée du début de cet horizon, plutôt qu'à l'horizon II.

2031 : 31 tessons et 3 individus. Grâce au mortier MO 1 présent dans cette structure, on peut la dater de l'horizon III.

2053 : 10 tessons et 1 individu. Une molette correspond au décor $n^{\circ} 13$ de la vallée de l'Aisne, daté de la deuxième moitié $\mathrm{du} \mathrm{VI}^{\mathrm{e}} \mathrm{s}$. Cette structure peut être datée de l'horizon III.

En conclusion sur la chronologie, on peut estimer que le site "Les Champs à Grès" a pu être implanté dès le milieu du $\mathrm{VI}^{\mathrm{e}} \mathrm{s}$. et exister jusqu'au $\mathrm{VII}^{\mathrm{e}}$ s., voire au début du $\mathrm{VIII}^{\mathrm{e}} \mathrm{s}$. avec le fond de cabane 2022. Cette datation correspond à l'horizon III de la vallée de l'Aisne pour la majorité des structures (mi VI ${ }^{\mathrm{e}}$-mi VII ${ }^{\mathrm{e}} \mathrm{s}$.) et un petit nombre de structures semblent plus tardives et correspondent à la deuxième moitié du VII ${ }^{\mathrm{e}}$ et au début du VIII ${ }^{\mathrm{e}} \mathrm{s}$. Beaucoup de structures contiennent trop peu de céramiques pour être datées.

L'étude des pâtes nous a montré la permanence de certains lieux de production antiques ou, tout du moins, l'exploitation des mêmes bancs d'argile avec les mêmes techniques de préparation pour une partie des tessons. Cependant, les techniques de façonnage et de finition ainsi que la typologie sont très différentes. Les ensembles du site s'intègrent dans le faciès régional de la céramique mérovingienne. 

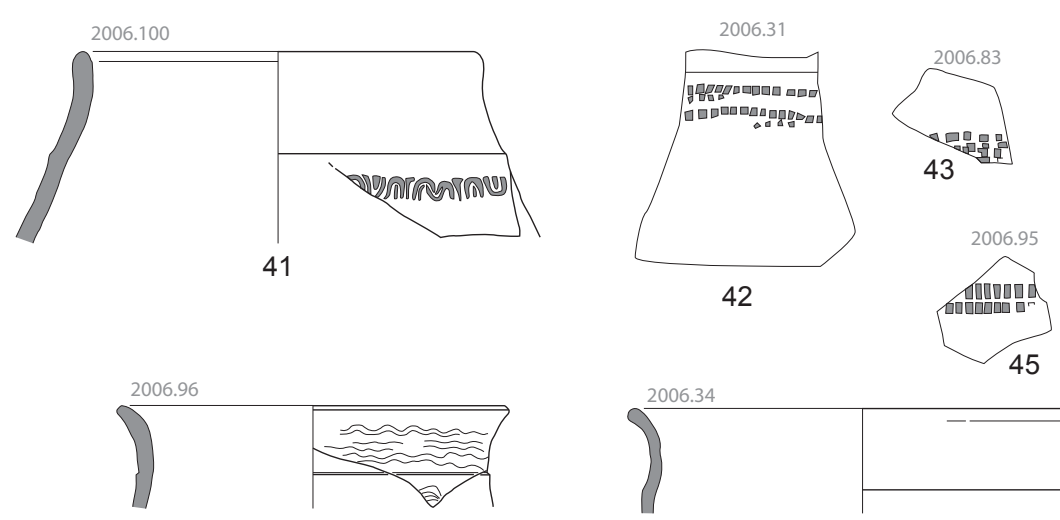

48

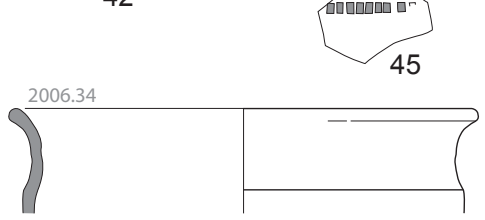

49
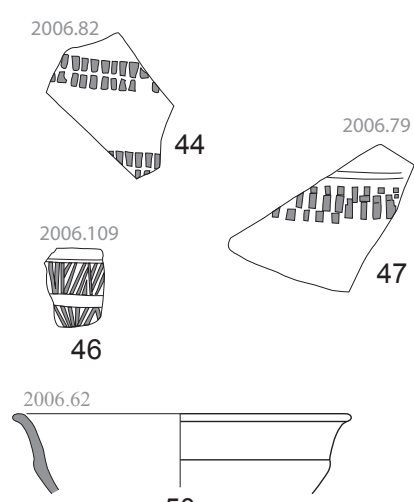

50
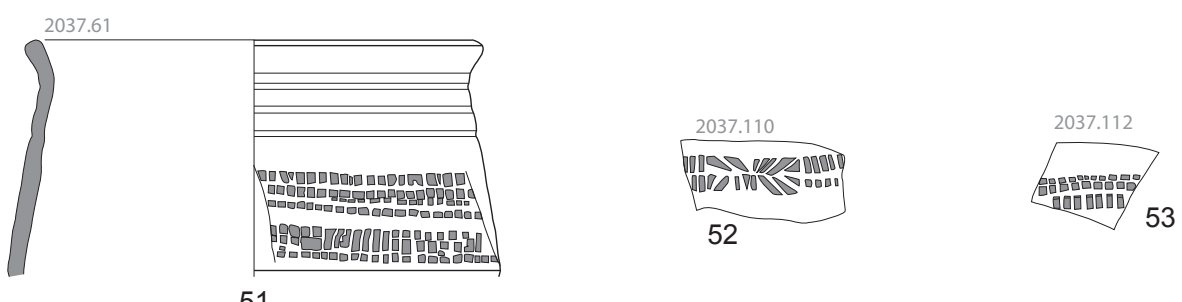

51

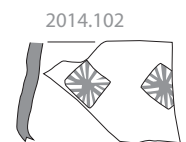

54

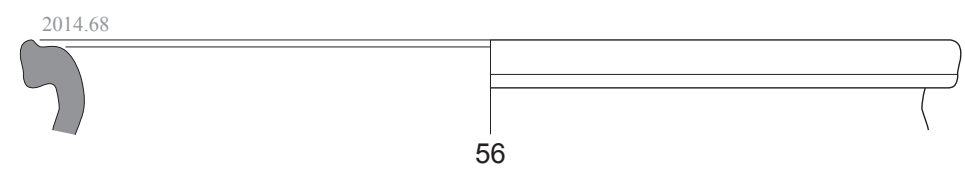

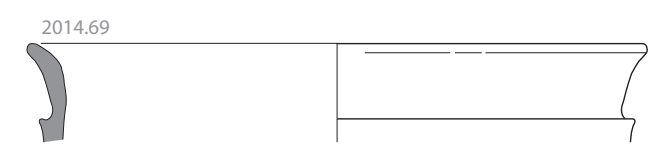

55
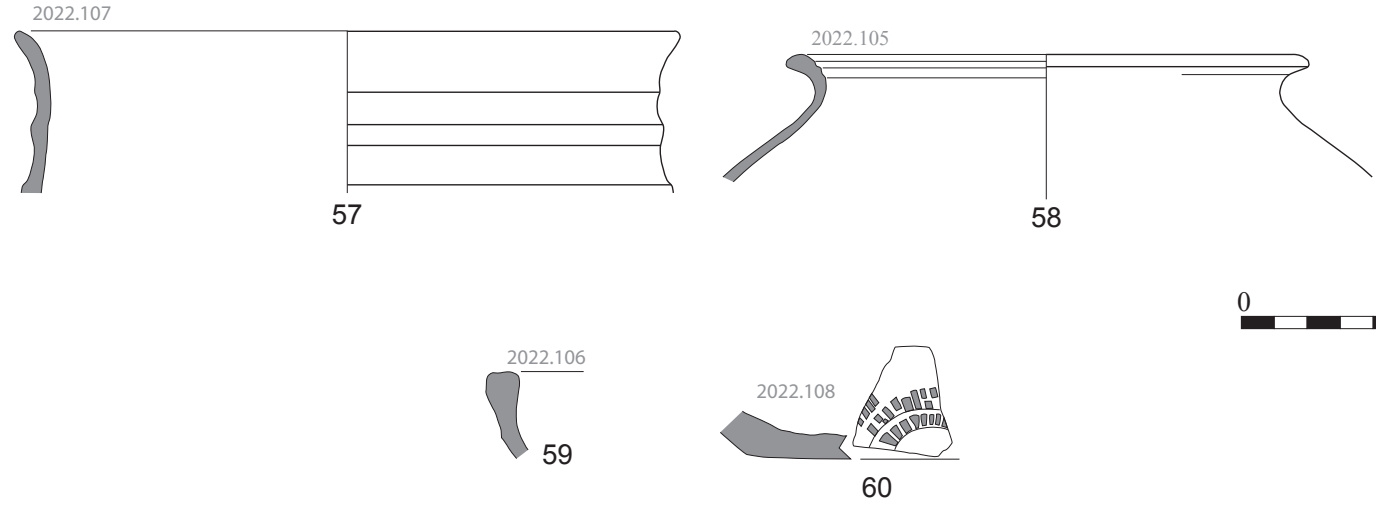

Fig. 22 - Céramique des structures 2006, 2037, 2014 et 2022 (éch. 1/3, dessin et DAO A. Corsiez, sauf n 42, dessin Pôle archéologique - CG 02).

\section{Catalogue}

1. CP VB1 : bord conservé à $30 \%$; S gris noirâtre, polie irrégulièrement ; $P$ à noyau gris mat et franges gris noirâtre ; $\varnothing: 11 \mathrm{~cm}$.

2. CP Cruche : bord conservé à $10 \%$ sur l'anse ; $S$ lisse, gris blanc ; $\mathrm{P}$ gris noir ; $\varnothing$ : Indét.

3. $\mathrm{CP}$ Cruche : $\mathrm{S}$ lisse, grise ; $\mathrm{P}$ à noyau brun jaune moyen et franges gris jaune à gris, comportant du quartz fin abondant, de rares inclusions rouges moyennement abondant.

4. CP Indét. : S lissée, gris sombre ; P gris clair.

5. CP A Indét. : $\mathrm{S}$ lissée irrégulièrement, gris sombre; P noir gris.

6. CP Indét. : bord conservé à $16 \%$; S lisse, gris noir ; P à noyau gris et frange gris noirâtre ; $\varnothing: 15 \mathrm{~cm}$. 
7. CP A Indét. : S lissée irrégulièrement, couleur hétérogène, dégradé de brun/brun orange ; $\mathrm{P}$ à noyau noir gris et franges brun gris ; $\varnothing$ : indét.

8. CP A Indét. : $S$ lisse, noire ; P brun gris, fine, comportant du quartz fin abondant.

9. CP A Indét. : S lissée, gris sombre ; P gris noir tirant sur le brun vers l'intérieur, comportant du quartz fin abondant.

10. CP A Indét. : $S$ lisse, gris sombre à gris clair ; $P$ gris mat, comportant du quartz fin très abondant.

11. CP B fin VB1 : bord conservé à $6 \% ; \mathrm{S}$ gris noirâtre, lissée ; P gris clair, fine, matrice feuilletée ; ø: $10 \mathrm{~cm}$.

12. CRB A EC3 : bord conservé à $6 \%$; $\mathrm{S}$ gris sombre à orangé grisâtre, rugueuse, traces de suies ; P gris noirâtre ; $\varnothing: 20 \mathrm{~cm}$.

13. CRB A P3 : bord conservé à $15 \%$; S grise, rugueuse ; P noire, comportant du quartz de fin à petit calibre peu abondant; $\varnothing: 15 \mathrm{~cm}$.

14. CRB B ? P1a : bord conservé à $14 \%$; S bleu gris, lisse, traces de suies ; P blanc grisâtre ; $\varnothing: 16 \mathrm{~cm}$.

15. CRB B ? P1a : bord conservé à $14 \%$; S gris orange, rugueuse ; P gris bleu avec des vacuoles, comportant du quartz fin clairsemé, du quartz de petit calibre abondant; $\varnothing: 16 \mathrm{~cm}$.

16. CRB A P1a : bord conservé à $23 \%$; S noir gris, rugueuse, traces de suie, caramel alimentaire et pellicule de calcaire interne ; $\mathrm{P}$ gris sombre à brun gris sombre ; $\varnothing: 13 \mathrm{~cm}$.

17. CRB P1a : bord conservé à $17 \%$; S polie, gris sombre ; P gris clair, fine; $\varnothing: 17 \mathrm{~cm}$.

18. CRB B ? P1b : bord conservé à $25 \%$; S rugueuse, couleur non uniforme gris sombre/noir brun, traces de suie sur l'intérieur de la lèvre ; $\mathrm{P}$ à noyau gris mat et franges gris sombre à gris brun ; ø: $15 \mathrm{~cm}$.

19. CP C Indét. : S lissée, noir gris ; P gris moyen.

20. CP A Indét. : $S$ lissée, gris noirâtre ; P gris mat.

21. CRB/CP Indét. : $S$ rugueuse, noire gris ; $\mathrm{P}$ gris jaune.

22. CP A Indét. : S rugueuse, grise ; P noir gris, comportant du quartz fin abondant.

23. CP A Indét. : S lissée irrégulièrement, zones rugueuses, gris noirâtre ; $\mathrm{P}$ gris noirâtre.

24. CRB A EC3 : bord conservé à $18 \%$; S rugueuse, noir gris avec un coup de feu grisâtre, épaisse couche de caramel alimentaire interne ; $\mathrm{P}$ noir gris ; $\varnothing: 14 \mathrm{~cm}$.

25. CP A EC3 : bord conservé à $11 \%$; S lissée, panse noir gris, le col dégradé de gris, caramel alimentaire interne ; P gris noir ; ø: $19 \mathrm{~cm}$.

26. CP A EC1 : bord conservé à $20 \%$; S lissée irrégulièrement, brun gris clair à brun gris sombre noirci, l'intérieur est gris noir, épaisse couche de caramel alimentaire interne et externe ; P moitié extérieure noire, moitié intérieure brun gris ; ø : $19 \mathrm{~cm}$.

27. CRB AEC4: bord conservé à $25 \%$; S rugueuse, noir gris ; P noir gris ; ø: $19 \mathrm{~cm}$.

28. CRB B Indét. : bord conservé à $4 \%$; $\mathrm{S}$ gris mat rugueuse ; P gris mat à noyau gris ; $\varnothing$ : indét.
29. CRB C P1b : bord conservé à $25 \%$; S rugueuse, gris noir ; P brun gris vif à gris sombre ; $\varnothing: 20 \mathrm{~cm}$.

30. CRB A P1a : bord conservé à $18 \%$; S rugueuse, gris noir ; P brun gris sombre; $\varnothing: 22 \mathrm{~cm}$.

31. CRB P1a : bord conservé à $41 \%$; S rugueuse, noir gris, pellicule de calcaire à l'intérieur, roussie par endroits ; P un tiers extérieur brun gris sombre, deux tiers intérieurs brun gris moyen; $\varnothing: 14 \mathrm{~cm}$.

32. CRB P1b : bord est conservé à $17 \%$; S gris noir non uniforme, rugueuse, trace de suie et pellicule de calcaire à l'intérieur ; P gris à noir brun ; ø : $14 \mathrm{~cm}$.

33. CRB A P1a : bord conservé à $20 \%$; S gris noir à noir gris, rugueuse, traces de suie ; $\mathrm{P}$ noir à gris noir ; $: 11 \mathrm{~cm}$.

34. CRB A P1b : bord conservé à $12 \%$; S gris noir à orange gris, rugueuse ; $P$ noir gris ; $\varnothing: 18 \mathrm{~cm}$.

35. CRB P1a: bord conservé à $11 \%$; S gris sombre, rugueuse, caramel alimentaire ; P gris sombre ; $\varnothing$ : $15 \mathrm{~cm}$.

36. CRB A P1b : bord conservé à $10 \%$; S gris noir à noir gris, rugueuse, traces de suie ; $\mathrm{P}$ gris clair ; $\varnothing$ : $15 \mathrm{~cm}$.

37. CRB A Indét. : bord conservé à $10 \%$; S noir gris, rugueuse ; P noire, fine ; $\varnothing: 13 \mathrm{~cm}$.

38. CRB A P3 : bord conservé à $11 \%$; S gris noirâtre à gris brunâtre, rugueuse ; $\mathrm{P}$ noire à noir brun ; ø: $13 \mathrm{~cm}$.

39. CM A Indét. : bord conservé à $10 \%$; S brun gris lisse, caramel alimentaire ; P noir gris ; $\varnothing: 10 \mathrm{~cm}$.

40. CM A Indét. : bord conservé à $15 \%$; S noir, lisse, négatif de fibres végétales abondantes ; $\mathrm{P}$ noire, comportant des fibres végétales abondantes ; $\varnothing: 11 \mathrm{~cm}$.

41. CP A ? VB2 : bord conservé à $15 \%$; S lisse, noir gris, zones brunes, pellicule de calcaire interne ; $\mathrm{P}$ moitié extérieure noir gris et moitié intérieure brun gris ; ø : $12 \mathrm{~cm}$.

42. CP A Indét. : S lissée, noir gris ; P brun gris sombre.

43. CP A Indét. : S lissée, noir gris ; P à noyau brun jaune sombre et franges noir gris.

44. CP A Indét. : S lissée, noir gris ; P à noyau gris sombre et fines franges noir gris.

45. CP A Indét. : S lissée, noir gris ; P à noyau gris et fines franges noir gris.

46. CP Indét. : $S$ lissée, gris noirâtre ; P à noyau gris et franges brun gris clair.

47. CP D Indét. : S lissée irrégulièrement, gris noirâtre ; P gris jaune, légèrement feuilletée.

48. CP A VB : bord conservé à $20 \%$; S abîmée, noir gris ; P noir gris ; $~: 12 \mathrm{~cm}$.

49. CRB D EC2 : bord conservé à $14 \%$; S noire, rugueuse à lisse ; P gris sombre ; ø: $14 \mathrm{~cm}$.

50. CP D EC2 : bord conservé à $7 \%$; $S$ lissée, gris sombre ; $P$ brune ; ø: $10 \mathrm{~cm}$.

51. CP A VB3 : bord conservé à $7 \%$; $S$ lissée, gris sombre ; P gris sombre; ø : env. $14 \mathrm{~cm}$.

52. CP Indét. : $S$ lisse, gris ; P à noyau gris noir, frange extérieure grise et frange intérieure brun gris vif.

53. CP Indét. : S rugueuse, gris noirâtre ; P orange brun vif. 
54. CP Indét. : S lissée, grise ; P à noyau gris jaune et franges gris mat.

55. CP D ? VB : bord conservé à $6 \%$; S gris mat à gris vif, rugueuse ; P gris brun clair ; $\varnothing: 18 \mathrm{~cm}$.

56. CRB P1a : bord conservé à $6 \% ; \mathrm{S}$ gris brun à gris sombre, rugueuse à lisse ; $\mathrm{P}$ blanc grisâtre ; $\varnothing$ : $28 \mathrm{~cm}$.

57. CP A VB4 : bord conservé à $10 \%$; S lustrée, noir gris ; $\mathrm{P}$ gris vif à gris mat; $\varnothing: 17 \mathrm{~cm}$.

58. CRB B P3 : bord conservé à $9 \%$; $\mathrm{S}$ gris à gris bleu, rugueuse ; P gris clair ; D. $15 \mathrm{~cm}$.

59. CRB A Indét. : bord conservé à $1 \%$; S gris noir, lissée irrégulièrement ; P noire ; ø : indét.

60. CRB Indét. : $S$ rugueuse, grise ; P à noyau gris, frange extérieure brun jaune moyen et frange intérieure gris jaune.

\section{Le mobilier paléométallurgique}

La présence de culots de forge de post réduction en position secondaire dans les structures 2031 et 2012 traduit sans doute la proximité d'une activité métallurgique (2 $308 \mathrm{~g}$ de scories de fer sur l'ensemble du site dont sept culots) et pourquoi pas d'une forge épisodique liée à la réparation d'outils (Leroy et al. 2001, p. 19).

\section{L'étude archéozoologique (G. JOUANIN)}

Les structures mérovingiennes ont livré 1086 restes osseux dont près de $60 \%$ ont été déterminés (tab. III). Les espèce rencontrées sont uniquement domestiques, le coq étant le seul représentant de la gente ailée. À l'exception du chien, toutes les espèces ont été consommées.

En nombre de restes, le porc domine légèrement le bœuf et plus amplement les caprinés (respectivement $44,6 \%, 42,1 \%$ et $13,3 \%$ du nombre de restes des trois principales espèces, NR3=594). En poids de restes, le bœuf est majoritaire face au porc et aux caprinés $(74,4 \%, 21,2 \%$ et $4,4 \%$ du poids de restes des trois principales espèces, PR3=17 097 g).

\begin{tabular}{|c|c|c|c|c|c|}
\hline mi VI ${ }^{\mathrm{e}}-\mathrm{mi} \mathrm{VII}{ }^{\mathrm{e}} \mathrm{s}$. & NR & $\%$ NR & PR & $\%$ PR & PM \\
\hline bœuf & 250 & 39,31 & 12718 & 65,72 & 50,87 \\
\hline porc & 265 & 41,67 & 3623 & 18,72 & 13,67 \\
\hline caprinés & 79 & 12,42 & 756 & 3,91 & 9,57 \\
\hline cheval & 20 & 3,14 & 2174 & 11,23 & 108,70 \\
\hline chien & 6 & 0,94 & 62 & 0,32 & 10,33 \\
\hline $\operatorname{coq}$ & 16 & 2,52 & 19 & 0,10 & \\
\hline Déterminés & 636 & 58,56 & 19352 & 93,17 & 30,43 \\
\hline Indéterminés & 450 & 41,44 & 1419 & 6,83 & 3,15 \\
\hline TOTAL & 1086 & 100 & 20771 & 100 & 19,13 \\
\hline
\end{tabular}

Tab. III - Dénombrement en nombre (NR) et poids (PR) des restes, Fresnoy-le-Grand «Les Champs à Grès», $\mathrm{mi} \mathrm{VI}{ }^{\mathrm{e}}-\mathrm{mi} \mathrm{VII}^{\mathrm{e}} \mathrm{s}$.

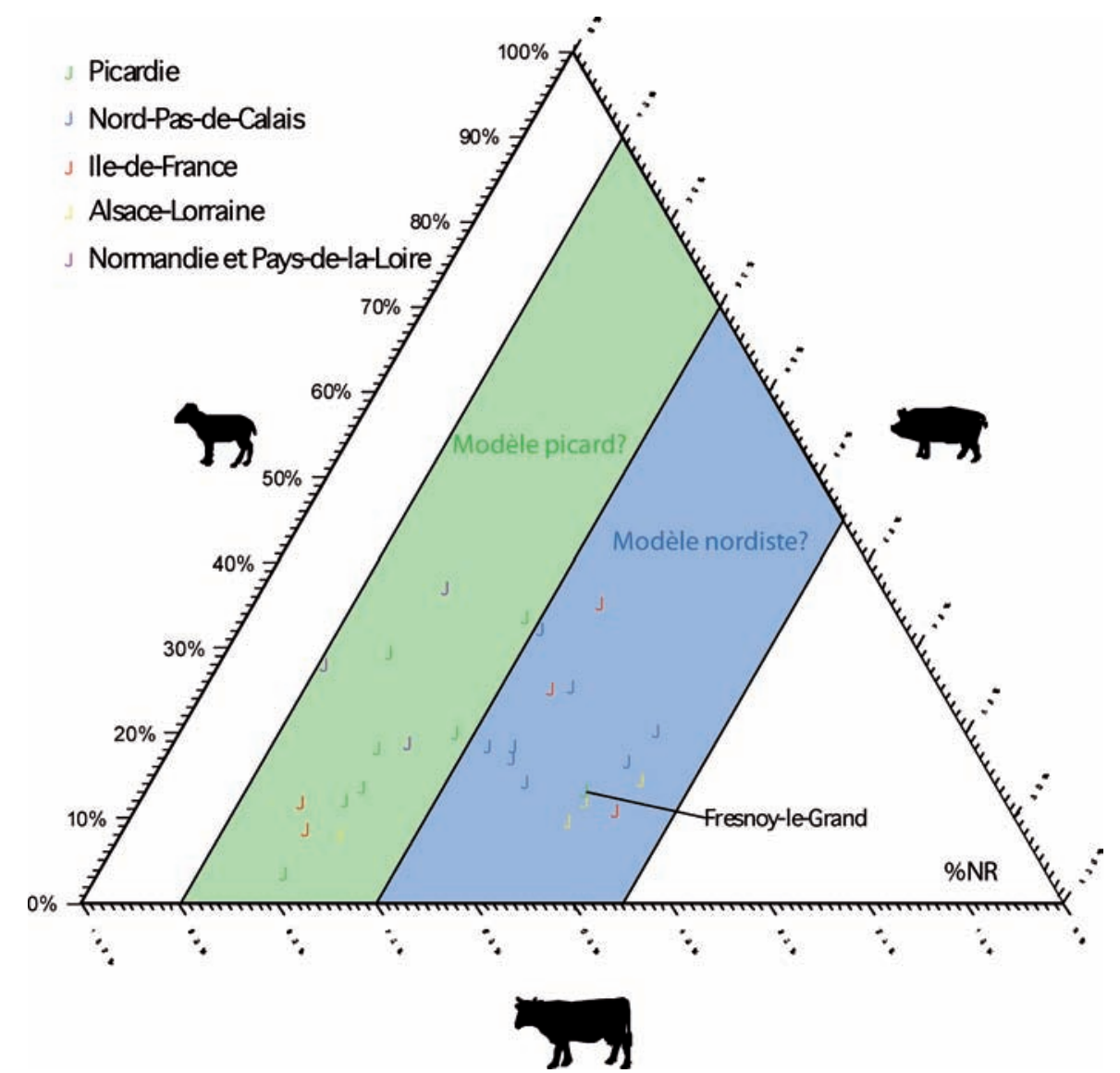

Fig. 24 - Proportions des trois principales espèces en nombre de restes (NR3) sur différents sites ruraux de la moitié nord de la France, période mérovingienne (données J.-H. YVINEC). 
Par ses proportions en nombre de restes, le site de Fresnoy-le-Grand se distingue des autres sites picards qui se caractérisent par une nette domination dubœuf sur le porc et les caprinés. Or les proportions observées à Fresnoy-le-Grand sont plus proches de celles enregistrées pour les sites du Nord - Pasde-Calais (fig. 24). La position géographique du site (à l'extrême nord du département de l'Aisne) pourrait expliquer cette situation. Cependant, la légère préférence donnée au porc peut également être le signe d'un certain isolement du site. En effet, espèce strictement bouchère, le porc convient parfaitement à une exploitation et une production de type « autosuffisant » (YvineC 1996, 1997). Cette hypothèse peut être étayée par l'abattage préférentiel des animaux parvenus à maturité pondérale chez les trois principales espèces. Ceci montre que la viande est privilégiée face aux autres produits exploités (lait et/ou laine chez les ovins, lait et/ou force chez les bovins). Cependant, pour les trois espèces, le nombre de dents permettant d'estimer les âges est faible et invite à la plus grande prudence quant à la représentativité des résultats obtenus.

Le site de Fresnoy-le-Grand "Les Champs à Grès" offre donc un profil particulier plus proche des sites nordistes que des sites picards. Ceci pourrait être dû à sa position géographique mais également à un système de production orienté sur la satisfaction des besoins de l'établissement plus que sur la production de denrées pouvant intégrer un réseau local d'échanges.

Les vestiges mérovingiens appartiennent à une unité agricole dont les structures sont situées, à l'exception de la cabane 2037, sur une bande de 15 à $20 \mathrm{~m}$ de large orientée nord-ouest / sud-est.

L'espace non aménagé entre les cabanes 2006 et 2012, la zone des poteaux 2052, 2053, 2054 et 2067 et la fosse 2014 pourrait être assimilé à une aire de circulation ouvrant sur ces différents ensembles et communicant aussi avec le bâtiment excavé 2041.

Mis à part quelques objets dont l'usage est relatif à des activités domestiques ordinaires (forces, couteaux, pierres à aiguiser, céramique culinaire), l'étude du mobilier a permis de mettre en évidence deux activités artisanales : forge et tissage (présence de pesons et d'aiguilles). La présence d'un fermoir d'aumônière, de vaisselle en verre et peut-être aussi d'une pince à épiler est cependant plus rare en contexte d'habitat.

\section{CONCLUSION}

Le site des "Champs à Grès", situé en périphérie d'une exploitation agricole à l'époque antique, semble abandonné à la fin du $\mathrm{III}^{\mathrm{e}} \mathrm{s}$. Il est réoccupé entre le milieu du VI ${ }^{\mathrm{e}}$ s. et le début du VIII ${ }^{\mathrm{e}} \mathrm{s}$. après J.-C. Ce hiatus entre la fin du $\mathrm{III}^{\mathrm{e}} \mathrm{s}$. et le milieu du
$\mathrm{VI}^{\mathrm{e}}$ s. est en accord avec les tendances observées en Picardie (Peytremann 2003, p. 178). Dans la région, la création de sites d'habitat rural intervient essentiellement aux $\mathrm{VI}^{\mathrm{e}}$ et au $\mathrm{IX}^{\mathrm{e}} \mathrm{s}$. L'hypothèse d'un contexte économique favorable a été avancée pour expliquer la réoccupation de sites antiques au $\mathrm{VI}^{\mathrm{e}} \mathrm{s}$. (Peytremann 2003, p. 354).

En comparaisons avec d'autres sites picards, l'occupation mérovingienne d'environ un siècle et demi apparaît comme légèrement courte (Peytremann 2003, p. 164). Compte tenu de l'emprise relativement limitée de la fouille, il n'est toutefois pas exclu que l'occupation se soit concentrée ou déplacée sur une autre unité agricole à la fin du VII siècle ou au début du siècle suivant.

\section{BIBLIOGRAPHIE}

BAYARD Didier (1989) - « Le village mérovingien du "Gué de Mauchamp" à Juvincourt-et-Damary, un des premiers habitats du haut Moyen Âge fouillés dans le Nord de la France ", Archéologie, grands travaux en Picardie, Autoroute A 26, Sanef, Revue archéologique de Picardie, Amiens, p. 101-110.

BAYARD Didier \& THOUVENOT Sylvain (1993) - «Étude de la céramique du Haut Moyen Âge $\left(V^{e}-X^{e} s\right.$. ) dans le département de l'Aisne (France) : premier bilan », PITON Daniel (dir.) - La céramique du $V^{e}$ au $X^{e} s$. dans l'Europe $d u$ Nord-Ouest, Actes du colloque d'Outreau (10-12 avril 1992), Nord-Ouest Archéologie, hors-série, p. 291-340.

BAYARD Didier (1994a) - « La céramique de la fin du III ${ }^{e}$ siècle et de la première moitié du IV ${ }^{\mathrm{e}}$ siècle après J.-C. et ses contextes en Picardie », dans TUFFREAU-LIBRE Marie \& JACQUES Alain (dir.) - La céramique du Bas-Empire en Gaule Belgique et dans les régions voisines, Actes de la table ronde de céramologie gallo-romaine, Arras, 8-10 octobre 1991, Revue du Nord, supplément 4.

BAYARD Didier (1994b) - «La céramique de l'habitat mérovingien de Goudelancourt-les-Pierrepont (Aisne) », Revue archéologique de Picardie, $\mathrm{n}^{\circ}$ 1/2, p. 65-79.

BET Philippe \& DELOR Anne (2000) - « La typologie de la sigillée lisse de Lezoux et de la Gaule centrale du HautEmpire, révision décennale ", SFECAG, Actes du congrès de Libourne, p.461-484.

BLONDIAU Lydie, CLOTUCHE Raphaël \& LORIDANT Frédéric (2001) - " Mise en évidence de répertoires de céramiques communes sombres dans la partieméridionale de la cité des Nerviens : l'apport de fouilles récentes ", SFECAG, Actes du Congrès de Lille-Bavay, p. 41-73.

CLOTUCHE Raphaël \& WILLEMS Sonja (2007) "Morphologie et technotypologie des productions rencontrées en Hainaut occidental en contexte rural ", SFECAG, Actes du Congrès de Langres, p. 275-294.

COLLART Jean-Luc (2006) - « L'époque romaine dans l'Aisne : un aperçu ", Mémoires du Soissonnais, Tome 3, 2002-2005, p. 203-226.

CORSIEZ Amélie (2001) - « La céramique précoce du village gallo-romain de Dourges/Noyelles-Godault et son contexte micro-régional : caractérisation d'un faciès ", SFECAG, Actes du Congrès de Lille-Bavay, p. 109-140. 
CORSIEZ Amélie (2006) - « La céramique du Bas-Empire dans l'ouest de l'Ostrevent », SFECAG, Actes du Congrès de Pézenas, p. 341-364.

CORSIEZ Amélie \& WILLLOT Jean-Michel (2007) - « La villa de Brebières : évolution de la céramique à travers les mutations d'un établissement rural », SFECAG, Actes du Congrès de Langres, p. 295-314.

CORSIEZ Amélie (2008) - « La céramique du site "La vallée de Neuville" à Neuville-Saint-Amand (Aisne) ", Revue archéologique de Picardie, n³/4, p. 163-190.

DERU Xavier (1996) - La céramique belge dans le Nord de la Gaule, Caractérisation, Chronologie, Phénomènes culturels et économiques, Louvain-la-Neuve.

DERU Xavier (2005) - « Les productions de l'atelier de potiers des "Quatres Bornes" aux Rues-des-Vignes (Nord) », SFECAG, Actes du Congrès de Blois, p. 469-478.

DESCHAMP Marie (2009) - « Le fond de cabane dans l'habitat rural du Haut Moyen Âge en Île-de-France. État des recherches et premier essai de synthèse » dans GENTILI François \& LEFEVRE Annie - L'habitat rural du Haut Moyen Age en Île-de-France, $2^{\mathrm{e}}$ supplément du Bulletin archéologique du Vexin français et du Val-d'Oise, Guiryen-Vexin, p. 61-71.

DUBOIS Stéphane \& BOURSON Véronique (2001) - "Première approche des faciès céramiques de la cité des Viromanduens (milieu du ${ }^{{ }^{e r}-f i n ~ d u ~ I I I ~}{ }^{\mathrm{e}}$ s.) », SFECAG, Actes du Congrès de Lille-Bavay, p. 183-202.

FEUGERE Michel (1985) - Les fibules de la Gaule méridionale de la conquête à la fin $d u V^{e}$ siècle après J.-C., Revue archéologique de la Narbonnaise, Supplément $n^{\circ} 12$, Paris, 509 p.

FEYEUX Jean-Yves (2003) - Le verre mérovingien du quart nord-est de la France, De Boccard, Paris, 286 p., 79 ill.

FLAMANT Yves (1984) - Histoire de Fresnoy, Comité d'action culturelle, Bohain-en-Vermandois, 257 p.

FLUZIN Philippe \& BAUVAIS Sylvain (2005) - « Analyses métallographiquesdesdéchetsdeforgedusitedeBazochessur-Vesle "Les Chantraines" (Aisne). Confrontation et perspective régionale ", Revue archéologique de Picardie, $\mathrm{n}^{\circ}$ spécial 22, p. 115-131.

GENTILI François (2009) - « Typologie et analyse spatiale des fonds de cabane du Haut Moyen Âge en Pays de France. L'exemple de Villiers-le-Sec et des sites environnants : Baillet-en-France, Le Mesnil-Aubry, Louvres et Villiers-le-Bel » dans GENTILI François \& LEFEVRE Annie (2009) - L'habitat rural du Haut Moyen Âge en Île-de-France, $2^{\mathrm{e}}$ supplément du Bulletin archéologique du Vexin français et du Val-d'Oise, p. 31-59.

GENTILI François, EPAUX Frédéric \& SIMARD Mélanie (2009) « L'apport de l'expérimentation archéologique pour la compréhension de l'architecture carolingienne à poteau planté : les exemples du chantier d'Orville (Vald'Oise) », Revue archéologique de Picardie, $\mathrm{n}^{\circ} 1 / 2$, p. 129144.

GORET Jean-François (1997) - « Le mobilier osseux travaillé découvert sur le site du "Vieux Château" de Château-Thierry (Aisne), IX ${ }^{\mathrm{e}}-\mathrm{XII}{ }^{\mathrm{e}} \mathrm{s}$. », Revue archéologique de Picardie, $\mathrm{n}^{\circ}$ 3/4, p. 101-136.
HARNAY Véronique \& THOUVENOT Sylvain (2001) - La céramique du Haut Moyen Âge sur l'Autoroute A29, extrait du rapport de fouille, Service régional de l'archéologie, Amiens.

HARNAY Véronique (2009) - " Le site du "Chemin de Croix", un habitat du Haut Moyen Âge aux abords de la villa royale d'Athies (Somme), Revue archéologique de Picardie, $\mathrm{n}^{\circ} 1 / 2$, p. 37-54

LEGOUX René (2005) - La nécropole mérovingienne de Cutry (Meurthe-et-Moselle), Mémoires publiés par l'Association française d'Archéologie mérovingienne, t. XIV, SaintGermain-en-Laye, $544 \mathrm{p}$

LEGOUX René, PERIN Patrick \& VALLET Françoise (2006) - « Chronologie normalisée du mobilier funéraire mérovingien entre Manche et Lorraine », Bulletin de liaison de l'Association française d'Archéologie mérovingienne, $\mathrm{n}^{\circ}$ hors série, $66 \mathrm{p}$.

LEROY Marc, MANGIN Michel, LAURENT Hervé, BOUKEZZOULA Mostefa \& RAÏSSOUNI Baraka (2001) - « La sidérurgie dans l'Est de la Gaule. L'organisation spatiale de la production de l'âge du Fer au Haut Moyen Âge », Gallia, n 57, p. 11-21.

MICHEL (1992) - Farbenführer, Munich 1992.

NICE Alain (1994) - « L'habitat mérovingien de Goudelancourt-les-Pierrepont (Aisne). Aperçu provisoire d'une unité agricole et domestique des $\mathrm{VI}^{\mathrm{e}}$ et VII $\mathrm{e}$ s. ", Revue archéologique de Picardie, $\mathrm{n}^{\circ}$ 1/2, p. 21-63.

PETITJEAN Michel (1995) - « Les peignes en os à l'époque mérovingienne. Évolution depuis l'Antiquité tardive ", Antiquités Nationales, n² 27, p. 145-191.

PEYTREMANN Edith (2003) - Archéologie de l'habitat rural dans le Nord de la France du IVe au XII siècle, Mémoires publiés par l'Association française d'Archéologie mérovingienne, t. XIII, Saint-Germain-en-Laye, vol. 1, 456 p.

PEYTREMANN Edith (2006) - «L'habitat déserté de Gungling à Grosbliederstroff (Moselle) IX ${ }^{\mathrm{e}}$ - début XVI siècle ", Archéologie médiévale, n 36, p. 57-113.

PY Michel Dir. (1993) - Dicocer 1. Dictionnaire des céramiques antiques (VII ${ }^{e}$ s avant $n$. è. - VII ${ }^{e}$ s. de n. è.) en Méditerranée nord-occidentale (Provence-Languedoc-Ampurdan), Lattara 6, Lattes.

THOUVENOT Sylvain (1998) - « L'atelier de potiers mérovingiens de Soissons (Aisne) », Revue archéologique de Picardie, $\mathrm{n}^{\circ} 3 / 4$, p. 123-187.

YVINEC Jean-Hervé (1996) - « Éléments de synthèse sur l'alimentation carnée durant le Haut Moyen Âge dans la Douaisis » dans L'homme et la nature au Moyen Âge, paleoenvironnement des sociétés occidentales, Actes du Ve congrès international d'archéologie médiévale, Grenoble 6-10 octobre 1993, Errances, Paris.

YVINEC Jean-Hervé (1997) - « L'élevage au Haut Moyen Âge en France du Nord et de l'Est : témoignages archéozoologiques. L'élevage médiéval », Ethnozootechnie, $\mathrm{n}^{\circ} 59$, p. 79-86 


\section{Les auteurs}

Thierry GALMICHE, Gilles DESPLANQUE

Service de la conservation des musées et de l'archéologie du Département de l'Aisne, pôle archéologique 1, rue William-Henri Waddington, F - 02000 LAON

Amélie CORSIEZ

Céramologue, Res Fabrum, doctorante Halma-Ipel 8164.

35 rue Jacques Fourrier, F - 02400 ESSÔMES-SUR-MARNE

Gaëtan JOUANIN, CRAVO

\section{Résumé}

Deux occupations distinctes ont été mises en évidence sur le site des "Champs à Grès" à Fresnoy-le-Grand (Aisne). La première, du III e siècle après J.-C., correspond à la périphérie d'une exploitation agricole. Les vestiges étudiés consistent en des fossés parcellaires, des foyers, quelques fosses et un cellier. Des sépultures à crémation et une tombe à inhumation ont également été mises au jour. La présence de deux tombes du ${ }^{\text {er }}$ siècle après J.-C. permet peut-être d'envisager une occupation précoce du secteur.

Des vestiges de l'époque mérovingienne ont aussi été trouvés. Ils appartiennent à une unité agricole dont la durée de vie s'étend de la seconde moitié du VI ${ }^{\mathrm{e}}$ siècle au milieu du siècle suivant, voire au début du VIII siècle. Huit cabanes et un bâtiment excavé de plus grande taille ont été découverts. La présence d'un bâtiment sur poteaux en bordure méridionale du site est possible. Au vu de la faible superficie étudiée, l'existence d'un ou plusieurs autres noyaux agricoles situés en dehors de l'emprise de fouille n'est pas exclue. Un hiatus a été mis en évidence entre le III e et la seconde moitié du VI ${ }^{\mathrm{e}}$ siècle. L'implantation mérovingienne apparaît ainsi comme la réoccupation d'un site abandonné depuis le III ${ }^{\mathrm{e}}$ siècle. Cette tendance s'explique, peut-être, par une remise en valeur de terres anciennement exploitées.

Mots-clefs : Antiquité, Mérovingien, Exploitation agricole, Cabane, Activité métallurgique, Archéozoologie, Incinération, Inhumation.

\section{Abstract}

Two different levels of occupation have been revealed on the site of the "Champ à Grès" at Fresnoy-leGrand (Aisne). The first one, dating from the III rd century A.D., corresponds to the periphery of a farm. The remains studied consist in boundary ditches, hearths, a few pits and a cellar. Some cremation tombs and a single inhumation tomb have also been excavated. The existence of two I st century A.D. tombs may possibly indicate an early occupation of this part of the site.

Some remains from the Merovingian period have also been discovered. They belong to a farming unit which lasted from the second half of the VI th century to the middle of the following century, perhaps even to the beginning of the VIII th century. Eight huts and a larger excavated building have been found. There may have been a construction built on posts on the south edge of the site. Taking account of the small surface excavated, the existence of one or several other farming units, outside this area, cannot be ruled out. There appears to be a gap between the III rd century and the second half of the VI th century. The Merovingian occupation thus appears to be the reoccupation of a site abandoned since the III rd century, which seems to indicate a tendency to redevelop previously farmed lands.

Keywords : Antiquity, Merovingian, Farming, Huts, Metalworking, Archaeozoology, Cremation, Inhumation.

Traduction : Margaret E Jean-Louis CADOUX.

\section{Zusammenfassung}

Am Fundplatz «Champs à Grès» in Fresnoy-le-Grand (Departement Aisne) wurden zwei unterschiedliche Siedlungsstrukturen nachgewiesen. Die erste wird in das 3. Jh. n. Chr. datiert und entspricht dem Randbezirk eines landwirtschaftlichen Betriebs. Die untersuchten Strukturen bestehen aus Parzellengräben, Feuerstellen, einigen Gruben und einem Vorratsraum. Zudem wurden Brandgräber und ein Körpergrab freigelegt. Zwei Gräber aus dem 1. Jh. n. Chr. legen eine frühe Besiedlung dieses Areals nahe. 
Es wurden ebenfalls Überreste aus merowingischer Zeit gefunden. Sie hören zu einem Gehöft, das von der zweiten Hälfte des 6. Jh. bis zur Mitte des darauffolgenden Jahrhunderts oder sogar bis zum Beginn des 8. Jh. existiert hatte. Acht Hütten und ein größerer eingetiefter Bau wurden freigelegt. Es ist nicht auszuschließen, dass am Südrand des Areals ein Pfostenbau gestanden hatte. Der ergrabene Bereich war recht klein, deshalb kann nicht ausgeschlossen werden, dass außerhalb des Areals eine oder sogar mehrere weitere bäuerliche Strukturen existiert haben. Zwischen dem 3. und der zweiten Hälfte des 6. Jh. wurde eine Unterbrechung der Siedlungskontinuität aufgezeigt. Die merowingische Siedlung erscheint in diesem Licht als die Neubesiedlung eines seit dem 3. Jahrhundert aufgegebenen Ortes. Diese Tendenz lässt sich vielleicht durch die erneute Bewirtschaftung bereits in früheren Zeiten genutzter Böden erklären.

Schlïsselwörter: Antike, merowingisch, landwirtschaftlicher Betrieb, Hütte, metallverarbeitende Tätigkeit, Archäologie, Brandbestattung, Körperbestattung.

Traduction : Isa ODENHARDT-DONVEZ (donvezservit@wanadoo.fr). 